OECD Environment Working Papers No. 62

\title{
A Characterisation
}

of Environmental Labelling

Guillaume Gruère and Information Schemes

https://dx.doi.org/10.1787/5k3z11hpdgq2-en 
Organisation de Coopération et de Développement Économiques

Organisation for Economic Co-operation and Development

03-Oct-2013

ENVIRONMENT DIRECTORATE

English - Or. English

ENVIRONMENT WORKING PAPER No. 62 - A CHARACTERISATION OF ENVIRONMENTAL LABELLING AND INFORMATION SCHEMES

By Guillaume Gruère, OECD

JEL Classification:Q56, Q58, L15

Keywords: Ecolabels; Environmental reporting; Information policy approaches; Institutional interactions; Product environmental footprints.

OECD Environment Working Papers are available at www.oecd.org/env/workingpapers.htm

JT03345571

Complete document available on OLIS in its original format

This document and any map included herein are without prejudice to the status of or sovereignty over any territory, to the delimitation of international frontiers and boundaries and to the name of any territory, city or area. 


\section{OECD ENVIRONMENT WORKING PAPERS}

This series is designed to make available to a wider readership selected studies on environmental issues prepared for use within the OECD. Authorship is usually collective, but principal authors are named.

The papers are generally available only in their original language English or French with a summary in the other if available.

The opinions expressed in these papers are the sole responsibility of the author(s) and do not necessarily reflect those of the OECD or the governments of its member countries.

Comment on the series is welcome, and should be sent to either env.contact@oecd.org or the Environment Directorate, 2, rue André Pascal, 75775 PARIS CEDEX 16, France.

OECD Environment Working Papers are published on www.oecd.org/env/workingpapers.htm

Applications for permission to reproduce or translate all or part of this material should be made to:

OECD Publishing, rights@oecd.org or by fax 33145249930.

COPYRIGHT OECD 2013 


\begin{abstract}
This report provides a comprehensive overview of the international landscape of environmental labelling and information schemes (ELIS), defined as policies and initiatives that aim to provide information about one or more aspects of the environmental performance of a product or service to external users. First, a review of initiatives and actors is used to build an institutional map of the diversity of schemes. Second, the universe of ELIS is dissected, based on a list of identified characteristics affecting the modes of communication of such schemes and the nature of the standards on which they are based. Lastly, the growth in ELIS is analysed by these identified characteristics, using a dataset of 544 ELIS introduced between 1970 and 2012 covering 197 countries.

Results from this analysis support the rapid in the number of ELIS, especially in the late 1990s and between 2007 and 2010. At the same time, these figures suggest that this growth might have slowed since 2010. The analysis also shows both the diversity and unequal growth of ELIS according to different characteristics. The growth in ELIS appears to be driven by the combination of an increase in the number of "traditional" ELIS, such as single-issue environmental seals, and the emergence of "more recent" types of ELIS, including quantitative reports. This combination highlights the tension between increased competition among similar ELIS, and the emergence of new schemes potentially less exposed to direct competition but facing larger entry challenges. The dataset also shows that the multiplicity of ELIS may not be present for all types of products and environmental areas in all countries.
\end{abstract}

These findings provide a contextual basis to look at evidence on the potential implications of having a multiplicity of schemes, and analyse the current and possible need for policy responses to identified challenges.

JEL classification: Q56, Q58, L15

Keywords: Ecolabels; Environmental reporting; Information policy approaches; Institutional interactions; Product environmental footprints. 


\section{RESUME}

Le présent rapport offre une vue d'ensemble sur le paysage des dispositifs d'éco-étiquetage et d'information (DEEI), définis comme étant les politiques et initiatives visant à fournir des informations sur un ou plusieurs aspects des performances environnementales d'un produit ou service à l'intention d'utilisateurs externes. Dans une première partie, on établit une cartographie institutionnelle de la variété des dispositifs, par un examen structurel des initiatives et des acteurs mettant en évidence leurs rôles et leurs interactions. Deuxièmement, on analyse l'univers des DEEI, sur la base d'un ensemble de caractéristiques déterminées concernant les modes de communication de ces dispositifs et la nature des normes sur lesquelles ils reposent. Enfin, on décompose la croissance des DEEI suivant les caractéristiques indiquées, au moyen d'un ensemble de données mondial couvrant 544 DEEI introduits entre 1970 et 2012 et couvrant 197 pays.

Les résultats de cette analyse confirment l'augmentation rapide notamment à la fin de la décennie 1990 et entre 2007 et 2010. En même temps, ces chiffres indiquent peut-être une moindre croissance depuis 2010. L'analyse montre aussi à la fois la diversité et la répartition inégale des DEEI en fonction des différentes caractéristiques. Elle souligne en particulier que la croissance du nombre des DEEI semble être due d'une part à celle des grandes catégories de DEEI classiques, telle que les marques environnementales à attribut unique, et d'autre part de l'apparition et l'accélération de l'introduction de nouveaux DEEI, comme les rapports quantitatifs environnementaux. Cette combinaison met en lumière la tension entre la compétition croissante parmi les DEEI similaires, et l'apparition de nouveaux dispositifs moins exposés à la compétition mais qui sont confrontés à des contraintes plus importantes d'entrée sur le marché. Il ressort enfin de l'ensemble de données qu'il n'y a pas toujours une multiplicité de DEEI pour tous les types de produits et de domaines dans tous les pays.

Ces résultats proposent un survol contextuel pour examiner les effets de la multiplication des dispositifs sur leur efficacité environnementale et leur impact sur les échanges commerciaux, et analyser de manière plus détaillée les réponses politiques observées et envisagées aux problèmes identifiés.

\section{Classification JEL : Q56, Q58, L15}

Mots-clés : Eco-labels; Rapports environnementaux; Politique d'approches informationnelles; Interactions institutionelles ; Empreintes environnementales des produits. 
ENV/WKP(2013)9

\section{FOREWORD}

This report is the first part of a larger project on the environmental, economic and international trade implications of the multiplicity in environmental labelling and information schemes. The work is conducted jointly under the leadership of the OECD Working Party on Integrating Environment and Economic Policies (WPIEEP) and the OECD Joint Working Party on Trade and Environment (JWPTE), with inputs from the Working Party on Resource Productivity and Waste (WPRPW).

This report has been authored by Guillaume Gruère of the OECD Secretariat. The author is grateful to experts from the institutions listed in the paper - including representatives from the Global Ecolabelling Network (GEN), the ISEAL Alliance, the Institut National pour la Recherche Agronomique, the International Trade Centre, TFT, and the United Nations (UN) Environmental Program - for their time and willingness to respond to questions and provide useful information. BigRoom Inc provided the data used in this paper with helpful comments. In addition to WPIEEP and JWPTE delegates, and specifically members of the Environmental Labelling Joint Task Force, the author would like to thank Shardul Agrawala, Ivan Haščič, Sylvain Rousset, Ysé Serret, Ronald Steenblik and Elizabeth Corbett of the OECD for valuable comments and suggestions. The project benefited from voluntary contributions from New Zealand.

This document does not necessarily represent the views of the OECD, its member countries or any of the cited institutions. It is published under the sole responsibility of the author. 


\section{EXECUTIVE SUMMARY}

This report provides a comprehensive overview of the landscape of environmental labelling and information schemes (ELIS), defined as policies and initiatives that aim to provide information about one or more aspects of the environmental performance of a product or service to external users. The analysis is based on a review of initiatives and databases, drawing lessons from the literature, additional information gathered from consultations with expert stakeholders in relevant institutions, and an empirical examination of a detailed international dataset of ELIS.

First, a review of initiatives and actors, outlining their roles and interactions, is used to build an institutional map of the diversity of schemes. The conceptual framework it suggests outlines in particular the importance of five types of institutions not directly involved in the information-dissemination exercise, which support, inventory, analyse or regulate their use and format. Each may have a role in managing the challenges associated with the observed increased number of ELIS.

Second, the universe of ELIS is dissected, based on a list of identified characteristics affecting the modes of communication of such schemes and the nature of the standards on which they are based. Interactions between criteria are discussed, outlining in particular three general categories of ELIS that range from seals to comprehensive reports. The importance of public involvement in this landscape is emphasised with a discussion of the multiple roles of governments around the use of ELIS.

Lastly, the growth in ELIS is analysed by identified characteristics, using a dataset of 544 ELIS introduced between 1970 and 2012 covering 197 countries. This dataset combines data from the EcoLabel Index and schemes referenced in OECD reports and other publications. General trends drawn from this dataset support the rapid increase in the number of ELIS, especially in the late 1990s and between 2007 and 2010. At the same time, these figures suggest that this growth might have slowed since 2010. The analysis also shows both the diversity and unequal growth of ELIS according to different characteristics, such as communication means, channels, scope, and the standards on which they are based. Several shifts are noted, including from organic certification and ecolabels to single-issue labels and ISO type III labels, from non-profit to privately-owned ELIS. A high proportion of ELIS in the database does not use life-cycle approaches and relies on standards based on non-product-related processes and production methods. A majority of these schemes also operate at the national level and a growing share of ELIS uses third-party auditing or verification. Most ELIS remain non-transparent in their standard-setting process, but there is a limited but relatively faster increase in transparent schemes.

The analysis further outlines the dual nature of the evolution of ELIS over time, driven by the combination of an increase in the number of "traditional" ELIS, such as single-issue environmental seals, and the emergence of "more recent" types of ELIS, including quantitative reports of greenhouse gas emissions. This combination highlights the tension between increased competition among similar ELIS, which could be slowing down, and the emergence of new schemes potentially less exposed to direct competition but facing larger entry challenges. The dataset is then used to show that the multiplicity of ELIS may not be present for all types of products and environmental areas in all countries, outlining the fact that observed increased competition is not incompatible with the presence of areas where only a few schemes have been initiated.

These results call for an assessment of the possible impacts of the observed growth and diversification in ELIS, in order to gauge the role of existing and potential policy responses. The next stages in the project will use this contextual basis to look at evidence on the potential implications of having a multiplicity of schemes, and analyse the current and possible need for policy responses to identified challenges. 


\section{TABLE OF CONTENTS}

ABSTRACT

A CHARACTERISATION OF ENVIRONMENTAL LABELLING AND INFORMATION SCHEMES.. 8

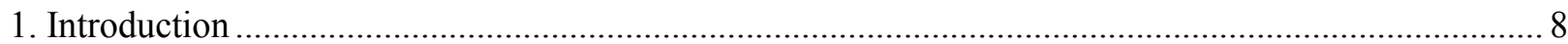

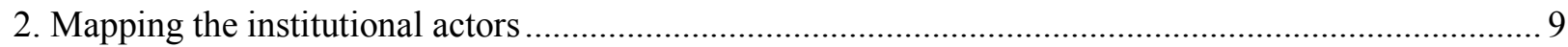

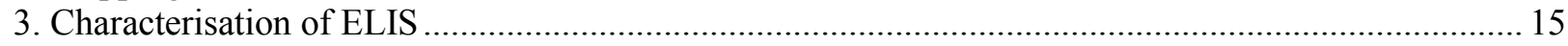

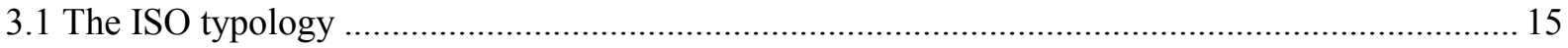

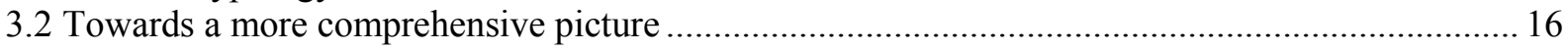

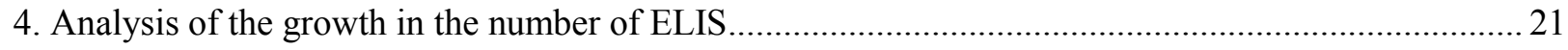

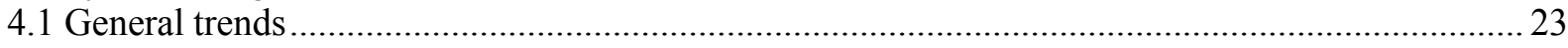

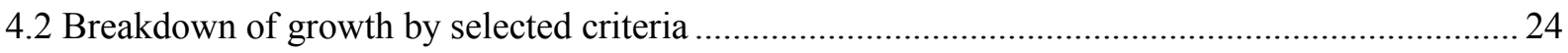

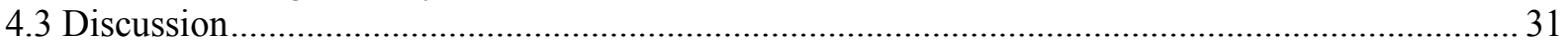

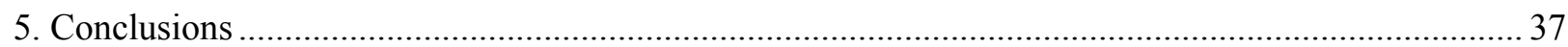

\section{Tables}

Table 1. Categories of institutional actors acting around ELIS users and suppliers ........................ 11

Table 2. ISO Standards and their main requirements.................................................................. 15

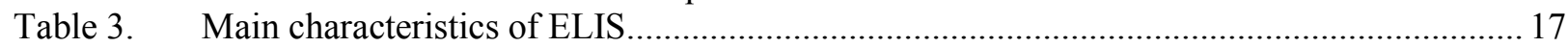

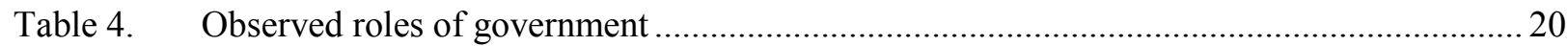

Table 5. Explanatory variables extracted from the combined ELIS dataset .....................................22

Table 6. Leading characteristics in the observed growth in the number of ELIS ..............................32

Table 7. Number of labelling schemes in four regions of OECD countries in 2012 ...................... 36

\section{Figures}

Figure 1. ELIS suppliers and users: Alternative routes for supplying information........................... 10

Figure 2. Mapping institutional actors within the boundary of rules and regulations ........................ 13

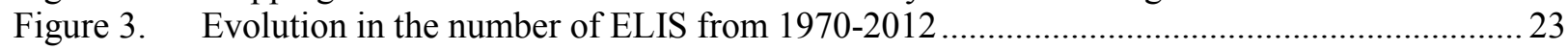

Figure 4. Evolution of the number of ELIS by main communication channels ............................... 24

Figure 5. Evolution of ELIS numbers by communication means ................................................. 25

Figure 6. Evolution of ELIS numbers by communication scopes.................................................26

Figure 7. Evolution of ELIS numbers in communication content.....................................................2 27

Figure 8. Evolution of the number of ELIS by standard characteristics .......................................... 29

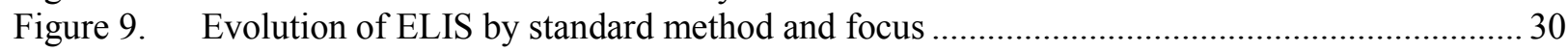

Figure 10. Evolution of the total number of ELIS by standard origin and scope .............................. 31

Figure 11. Breakdown of growth in dominant versus emerging characteristics ............................. 34

Figure 12. Introduction of Registered Trademarks using the word 'Green' in selected countries..... 45

Figure 13. Introduction of Registered Trademarks using the word 'Sustainable' ............................. 46

Figure 14. Introduction of Registered Trademarks using the word 'Natural' .................................... 46 


\section{A CHARACTERISATION OF ENVIRONMENTAL LABELLING AND INFORMATION SCHEMES}

\section{Introduction}

Environmental labels and information schemes (ELIS) have been used for over forty years. The first public eco-labelling schemes were developed in the 1970 s, with a view to providing seals on products with the best environmental characteristics. Single-issue certification schemes and individual private standards followed, in the 1980s and 1990s (OECD, 1991 and 1997a). The last fifteen years have seen a multiplication of ELIS of varying scope, size, nature and effectiveness (see, e.g., Crespi and Marette, 2005; Cohen and Vandenbergh, 2012; Hatanaka et al., 2005; European Commission, 2012; Vergez, 2012). As a result, the market has been characterised by the co-existence of a large number of ecolabels, claims, declarations and other modes of transmitting information on the environmental characteristics of products.

The increased number and diversity of ELIS has raised questions about their relevance and effectiveness as environmental policy instruments, and the potential trade effects they may have (Lohr, 1998; Marette, 2007; OECD, 1999 and 2009a). In particular, some reports have argued that competing labelling claims could potentially contribute to consumers' confusion (Dahl, 2012; Fliess et al., 2007; OECD, 1997a and 2007). Reports of misleading claims, often exaggerating environmental performance, a practice termed "greenwashing" (Dahl, 2012; Kewalramani and Sobelsohn, 2012), have reportedly reduced the confidence of consumers in labels (e.g., Daniells, 2013; OECD, 2010a). At the same time, companies have increasingly employed reporting mechanisms to inform their suppliers and investors of their environmental footprints, but they have used different and at least partially inconsistent methods, making it difficult to provide valid comparisons (e.g., Ernst \&Young and Quantis, 2010; EVEA et Savin Martinet Associés, 2012).

A number of international initiatives, public and private, have been launched recently to respond to this fragmentation of information and its potential economic, environmental or international implications. Companies, non-profit organisations and international organisations have engaged in discussions and introduced initiatives to respond to the related issues faced by their constituents and clients. A few policy proposals have also been put forward to cope with unwanted effects induced by the multiplication of schemes, either via regulatory frameworks guiding private claims (OECD, 2010b), regulatory agencies orienting consumers towards schemes that perform better (Overgaard, 2012), or proposed harmonised environmental labelling policies to address the inconsistency in standards and possible consumer effects associated with the "proliferation" of schemes (e.g., République Française 2010; European Commission 2013).

Serving as an introduction to a broader impact and policy study, this paper aims to provide a characterisation of the diversity and growth in ELIS. ELIS are defined here as policies and initiatives that aim to provide information to external users about one or more aspects of the environmental performance of a product or service. The users may or may not require the information, but they can have access to it. ELIS can provide communication channels between business or government on the one hand and business, governments and consumers on the other hand. In particular, a large number of ELIS involves business-tobusiness (B2B) and business-to-consumer (B2C) communication. They can also be developed and managed by public agencies, private companies, non-profit organisations or a combination thereof. As 
defined, ELIS include environmental performance information publically made by companies (e.g., an annual report with environmental information). By contrast, self-reporting initiatives, such as accounting or company greening practices, are not considered in this definition if they are not meant for external publication. This definition also does not include a larger set of generic information tools that are meant to provide information about product claims and characteristics, for instance via internet databases.

More specifically, the objectives of this paper are to provide an overview of the key institutions involved in or around ELIS, to differentiate the various characteristics of ELIS, and to assess the reported growth in the number of these schemes. The analysis is based on a review of initiatives and databases, drawing lessons from the literature, additional information gathered from consultations with expert stakeholders in relevant institutions, ${ }^{1}$ and the empirical examination of a detailed international dataset of ELIS. At the same time, given the complexity of the landscape and the dynamism in the sector, the report does not claim to provide an exhaustive view of all existing efforts. In particular, the dataset used, while relatively comprehensive, is not meant to be a complete international inventory.

The rest of the paper is organised in four sections. The first section reviews the roles of institutional actors around ELIS to provide a contextual introduction to their diversity. The second section discusses the main characteristics and criteria for differentiation, and the third section provides an empirical analysis of a comprehensive set of ELIS. The final section draws conclusions from this introductory analysis and the implications it may have on the project's next steps as it moves towards impacts and policies.

\section{Mapping the institutional actors}

ELIS can be schematically associated with two generic types of directly involved actors; ELIS suppliers and ELIS users.

ELIS suppliers, consisting of single or multiple entities, contribute to a number of roles, including: setting up a standard, applying it to internal or external products or services, verifying its implementation, and promoting it outside. Examples include companies publishing environmental declarations, non-profit organizations offering certifications services, or government-led ecolabels. They define the information that will be delivered, on what product, under what format, and the way in which it will be conveyed to targeted users. The observed diversity in schemes is matched by the diversity of ELIS suppliers.

Still, a fundamental distinction separates schemes ruled internally by producers from those depending on external actors. Companies can decide to undertake most required actions internally, even if using an auditor in the initial phase, and communicating its results and processes in a transparent manner. For instance, Nestlé Waters is involved in a number of environmental programs (packaging, recycling) internally, while communicating its performance via the Internet and other media. ${ }^{2}$ Alternatively, they may use an external certification scheme (whether private of public) to assess their products or services and monitor their environmental performance. Lipton Tea (Australia) uses certification from the Rainforest Alliance on some of its products. ${ }^{3}$ The two routes are shown in Figure 1.

1 In particular, consultation were held with representatives from the Global Ecolabelling Network (GEN), the ISEAL Alliance, the Institut National pour la Recherche Agronomique, the International Trade Centre, TFT, the United Nations (UN) Environmental Program, and informally with participants to international meetings organized by the OECD, the UN Forum on Sustainability Standards, and the World Trade Organization.

2 See http://www.nestle-waters.com/environment/environmental-performance .

See http://www.rainforest-alliance.org/multimedia/lipton-au . 
While both routes have been used, they represent widely different approaches to reaching an environmental objective. The "certification" route may be preferred because the certifying body provides increased credibility in the eye of users. But employing this route also runs some reputational risk if the certifier is found at fault, even for a completely different product or company. ${ }^{4}$ Furthermore, it may require costly supply-chain adaptations. Still, a majority of companies prefer to use this route, thereby outsourcing their environmental strategy. In contrast, the "private standard" route allows the company to choose its objectives, and follow its preferred method, in a potentially more efficient way, and to better control reputation risks, provided it ensures full transparency (Mak, 2013). At the same time, self-declarations are generally viewed with greater scepticism by users who may perceive them as greenwashing. Some large companies, often with strong brand power and reputation on which they can rely, increasingly prefer to use this route to set up their own environmental strategy (Comas Martí and Seifert, 2012). ${ }^{5}$

Figure 1. ELIS suppliers and users: Alternative routes for supplying information

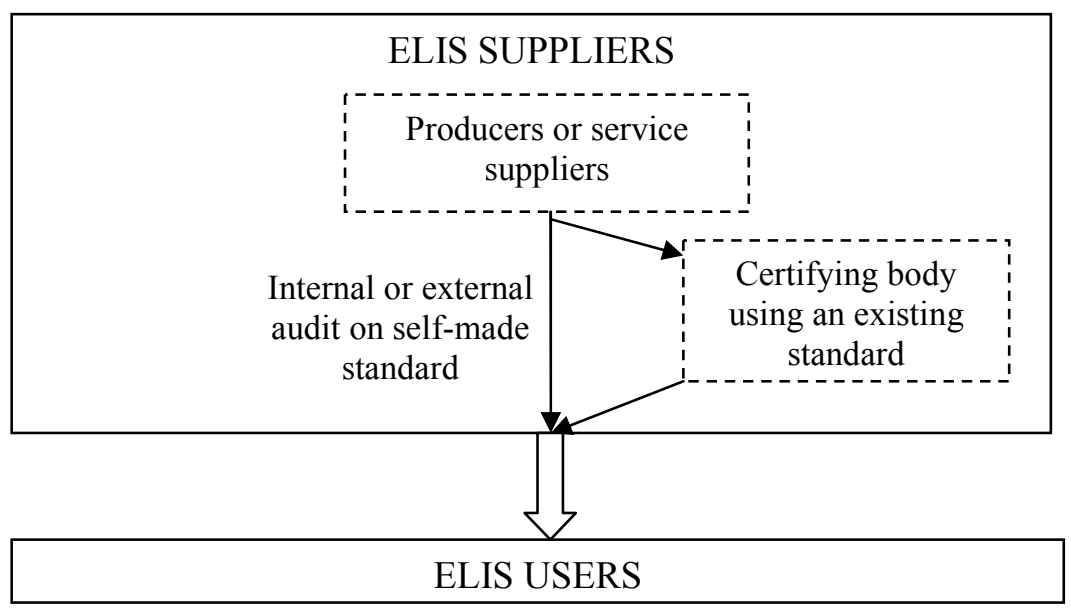

ELIS users also vary according to the scheme, but are generally easier to identify. Consumers, businesses and governments are their major constituents. While called "users" here, they may or may not use the information provided by the scheme. For instance, many environmental labels on household consumer products are recognised by a small proportion of consumers, and used by an even smaller proportion of consumers in their purchasing decision (e.g., OECD, 2011b). ${ }^{6}$ Similarly, business-to-business communication may be needed to fulfil a scheme or requirement set by a buyer, but it may also not be of direct use to another buyer provided with the same information.

ELIS suppliers and users are surrounded by institutional groups indirectly involved in the use of ELIS. These can be separated into five main categories. First, several associations or supporting groups of ELIS suppliers have been formed among similarly designed schemes to reach mutually beneficial goals. Second, several external initiatives have focused on generating databases to provide guidance to specific

$4 \quad$ Recent research and news reports have for instance criticised the Marine Stewardship Council for using allegedly dubious criteria to assess fisheries' sustainability (Christian et al., 2013; Zwerdling and Williams, 2013).

5 A third type of process is observed for mandatory information or labelling requirements; in this case producers have to comply with requirements.

Some widely used environmental labels, however, do have a high level of recognition, including wellestablished ecolabels such as the Nordic Swan in Norway or the New Zealand Environmental Choice program. 
users of ELIS. A third group of institutions has contributed to discussions around ELIS and the policy environment surrounding these schemes. The fourth group includes recently created platforms of private companies and policy supporting institutions moving toward commonly designed schemes. Lastly, national and international institutions are setting standards and regulating ELIS. Table 1 provides a rapid characterisation of the five categories with examples.

Table 1. Categories of institutional actors acting around ELIS users and suppliers

\begin{tabular}{|c|c|c|c|}
\hline Category & Characteristics & Goals & Main examples \\
\hline Supporting Institutions & $\begin{array}{l}\text { Similarly } \\
\text { designed, often } \\
\text { similar } \\
\text { ownership and } \\
\text { principles of } \\
\text { operations }\end{array}$ & $\begin{array}{l}\text { Mutually beneficial } \\
\text { goals: guiding } \\
\text { principles, self- } \\
\text { reinforcement and } \\
\text { promotion, codes of } \\
\text { conducts, peer } \\
\text { reviews. }\end{array}$ & $\begin{array}{l}\text { International Federation of Organic } \\
\text { Agriculture Movements (IFOAM), Global } \\
\text { Ecolabelling Network (GEN), ISEAL } \\
\text { Alliance, World Green Building Council. }\end{array}$ \\
\hline Inventorying institutions & $\begin{array}{l}\text { Managers of } \\
\text { inventories with } \\
\text { expanding } \\
\text { number of } \\
\text { schemes }\end{array}$ & $\begin{array}{l}\text { Provide guidance to } \\
\text { targeted users } \\
\text { (companies, } \\
\text { consumers, others), } \\
\text { acting as } \\
\text { intermediates }\end{array}$ & $\begin{array}{l}\text { EcoLabel Index, Greener Choices } \\
\text { ecolabels, BASF Select Ecolabel Manager, } \\
\text { UL Environment, Greenext GreenCode Info } \\
\text { Index; Japanese Environmental Label } \\
\text { Database; ITC Standard Map. }\end{array}$ \\
\hline $\begin{array}{l}\text { Policy support } \\
\text { institutions }\end{array}$ & $\begin{array}{l}\text { External } \\
\text { observers, such } \\
\text { as think tanks } \\
\text { and international } \\
\text { organisations }\end{array}$ & $\begin{array}{l}\text { Supporting discussion } \\
\text { and providing } \\
\text { analysis for } \\
\text { practitioners and } \\
\text { policy makers }\end{array}$ & $\begin{array}{l}\text { OECD, UNEP, UNFSS (consortium of } \\
\text { UNEP, UNCTAD, UNIDO, FAO, ITC), } \\
\text { ENTWINED, Resources for the Future, } \\
\text { COSA, academics, research organisations, } \\
\text { and private consulting firms. }\end{array}$ \\
\hline $\begin{array}{l}\text { Platforms and } \\
\text { consortiums }\end{array}$ & $\begin{array}{l}\text { Networks } \\
\text { regrouping } \\
\text { mostly policy } \\
\text { support and } \\
\text { ELIS suppliers } \\
\end{array}$ & $\begin{array}{l}\text { Supporting the } \\
\text { development and use } \\
\text { of common principles } \\
\text { and standards for } \\
\text { companies }\end{array}$ & $\begin{array}{l}\text { The Global Reporting Initiative (GRI), the } \\
\text { UN Global Compact, the Sustainable } \\
\text { Consortium, the Product Sustainability } \\
\text { Forum, the B Team. }\end{array}$ \\
\hline Framing institutions & $\begin{array}{l}\text { National } \\
\text { governments or } \\
\text { standards } \\
\text { setting bodies }\end{array}$ & $\begin{array}{l}\text { Providing policy } \\
\text { frameworks around } \\
\text { ELIS }\end{array}$ & Regulatory authorities, ISO, WTO, FAO. \\
\hline
\end{tabular}

\footnotetext{
Sources: Author, based on institutional websites.
}

Abbreviations: ITC: International Trade Centre; UNEP: United Nations Environmental Program, UNFSS: United Nations Forum on Sustainability Standards; UNCTAD: United Nations Commodities Trade and Development, FAO: United Nations Food and Agricultural Organization, ENTWINED: Environment and Trade in a world of Interdependence; COSA: Committee on Sustainable Assessment, ISO: International Organizations for Standardization, WTO: World Trade Organisation.

Note: The B team was created in 2013, as a group of entrepreneurs representing a few multinational companies, but it aims at reaching other companies, national governments and international organisations.

Supporting institutions have played a prominent role in advancing the cause and the use of specific types of ELIS. Among leading institutions, the International Federation of Organic Agriculture Movements (IFOAM) has acted as the sole engine of harmonisation in the highly fragmented international market of organic certifications and continues to be the main support group in the advancement of these schemes. The Global Ecolabelling Network (GEN) is a non-profit association, launched in 1994, which regroups organisations promoting ISO Type I ecolabels (characteristics described below) in over fifty countries. Its mission is to support its members, contribute to international discussions and promote the use of ecolabels and environmental products. Founded in 2002, the ISEAL Alliance has been developing and implementing codes of good practices (including on transparency, credibility, compliance, and impacts) for a growing number of standard-setting members, representing some of the most widely used single-issue 
environmental labels. ${ }^{7}$ Its members include the Marine Stewardship Council and the Rainforest Alliance. The World Green Building Council co-ordinates and sustains a network of 90 national green building councils, each of which manages a network of industry members working towards environmentally performing buildings. All these groups support the goals of their members and conduct outreach activities for their potential users. While reinforcing the objectives of their members, and ensuring that they can remain credible options, they support actions to reduce the continued fragmentation of schemes.

The second group, constituted of inventorying institutions, is not directly involved in ELIS, but rather assisting targeted ELIS users. Some of these schemes originate from private companies, with the intention to guide their customers. Greener Choices was set up in the United States in 2005 by the publication Consumer Reports, as an Internet tool to guide consumers facing a growing number of environmental labelling schemes and to deter greenwashing claims. The EcoLabel Index website, developed by the company BigRoom, based in Canada, is the largest inventory of international environmental labelling schemes. It provides this information to Internet users and with more details to subscribers. On the industry side, BASF Select also maintains a large database of ELIS, with a significant range of technical details, intended specifically for use by their customers and partners. At the same time, several public institutions have also developed databases for public guidance. The International Trade Centre (ITC) has developed Standards Map, an internet-based website that repertories detailed information on over 100 standards to its users, and is in the process of introducing a tool to help exporters decide which scheme to use. The Ministry of Environment in Japan has developed an Environmental Label Database. ${ }^{8}$ Some of the major public-procurement agencies have also set up their own inventorying systems (e.g., UNOPS, 2009). While some of them may be developed for commercial rather than environmental purposes, all these initiatives aim at providing guidance to their respective users, and were created largely to respond to a demand for orientation induced by the multiplication of ELIS.

Policy-support institutions constitute the third category of actors and play an intermediate role between policy makers and other ELIS stakeholders. They facilitate discussions among institutional actors around the use of ELIS and provide analytical support on various issues. The United Nations Environment Program (UNEP) has long been active in this area. It is currently leading a programme on Product Sustainability Information, with the goal of developing common principles around the large number of tools providing information on environmental performances, including ELIS. In early 2013, five United Nations bodies launched the UN Forum on Sustainable Standards (UNFSS), with the objective of providing "information and analysis on voluntary sustainability standards (VSS) with a particular focus on the potential value of VSS as tools for developing countries to achieve their sustainable development goals" (UNFSS, 2013). Think-tanks, research-based organisations, academic institutions and private consulting firms are also involved in the dialogue around the use of ELIS. All these actors are generally independent from ELIS suppliers, and most often indirectly related with ELIS users. They provide a thirdparty view and play a facilitating role that is most often targeting the policy world. Several international initiatives in this category have been introduced partially to respond to the multiplication of schemes and its implications for suppliers and users, but their main role has been to observe the issues associated with ELIS and to propose and discuss solutions.

The fourth category, platforms and consortiums, could be considered a recently introduced hybrid ELIS support group. It combines private ELIS suppliers and policy support institutions with the goal of developing, using and promoting similar standards or principles. A number of them have been founded in the last decade by large companies with inputs and participation from academics, non-governmental organisations and sometimes government agencies. They collaborate to reach commonly acceptable and

\footnotetext{
$7 \quad$ "Single-issue label" is a simplified denomination; the terms single phase single or multi attribute labels could be used instead to refer to the fact that they focus on one phase of the life cycle of a product.

8 See: http://www.env.go.jp/policy/hozen/green/ecolabel/f01.html.
} 
credible standards as support for their own sustainability reporting or labelling schemes on a large range of private goods. The Global Reporting Initiative (GRI) is a non-profit organisation promoting the use of a common reporting framework on sustainability, with over 500 members, including businesses, civil society groups and inter-governmental agencies. The UN Global Compact is a network of businesses and civil society, focusing on ensuring that businesses commit to ten principles in the areas of human rights, labour, the environment, and anti-corruption. The $8^{\text {th }}$ principle encourages companies to follow sustainable practices for instance with the use of transparent practices that follow the internal route of Figure 1. The Sustainable Consortium was set up by Wal-Mart Co. and other companies associated with academic researchers to determine a common set of sustainability standards for categories of products they deliver to consumers. With a more mixed model, involving governmental agencies, the Product Sustainability Forum is a platform set up by companies and the United Kingdom's government to support the use of specific reporting schemes. Similarly, the Agence de l'Environnement et de la Maîtrise de l'Energie (ADEME) and the AFNOR Association set up, in 2008, at the request of the French government, the "Affichage environnemental des produits" Platform bringing together industry and stakeholders in order to develop general and sectoral product environmental footprinting methods. A number of these schemes were also designed to respond to the fragmentation of ELIS, by facilitating discussion but also moving towards implementation.

Figure 2. Mapping institutional actors within the boundary of rules and regulations

Wide arrow: flow of information on environmental performance. Dashed arrows: communications and influences. Dotted arrows: indirect links.

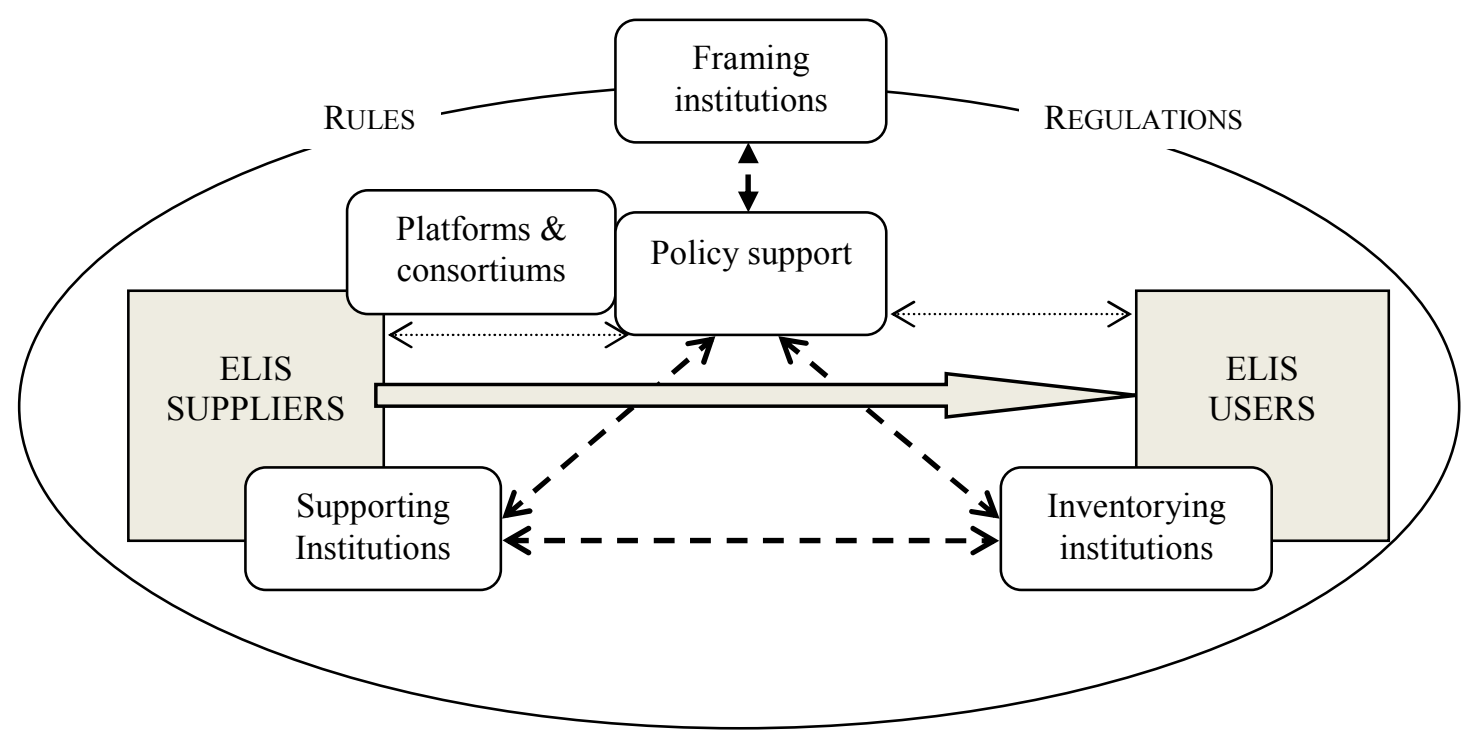

The last category, framing institutions, regroups institutions that are framing the ELIS landscape. The World Trade Organization (WTO) applies rules that are not specific to ELIS but relevant to their use and especially to the interaction of governments with potentially trade-distorting ELIS. The International Organization for Standardization (ISO) is the most widely known international standard setter, serving as a reference for the WTO. The ISO 14020 standard series has defined internationally accepted guidance towards the use of claims, declarations and ecolabels. The ISO is also the forum where methods and measures of environmental impacts, including those related to carbon and water footprints, are being discussed. At a lower scale, national governments provide rules that frame the use of ELIS. In particular, a number of countries have published guidance documents to regulate the use of private environmental claims. The role of these institutions, even if very diverse across countries, is to define and implement rules and regulations to avoid the misuse of ELIS instruments. 
Figure 2 gives a schematic representation of the five types of institutional actors and their relationship with the suppliers and users of ELIS. Box 1 provides an example of institutional interactions in the case of the Japanese Eco Mark ecolabel. Within a set of rules and regulations, specific suppliers of ELIS associate themselves with support groups or platforms to get organised and more effectively reach users. Inventorying institutions help orient ELIS users to schemes using some of the principles developed by support groups. Policy support institutions interact with different actors, contribute to platforms, facilitate discussions, conduct analysis, and report to the framing institutions.

\section{Box 1. ELIS and institutions: The case of the Japanese Eco Mark ecolabel}

Among the first ecolabel programs, set up in 1989, the Eco Mark provides a certification of a significant range of environmentally superior products. The ELIS supplier in this case is the Japanese Environmental Association, which sets and manages the standard certification and implementation. Targeted ELIS users are consumers that can recognize the product based on its trademark protected logo.

At the international level, the Japanese Environmental Association is a member of the Global Ecolabelling Network, an ELIS support group. It has concluded mutual recognition agreements with other ecolabels including the Korean EcoLabel, the Nordic Swan, the Thai Green Label, and New Zealand's Environmental Choice. This allows Eco Mark labelled products to obtain these other labels when sold in their respective markets and conversely other ecolabelled products to carry the Eco Mark on the Japanese market. The Eco Mark is also listed in several databases, including the EcoLabel Index (ELIS guides) and used as a reference by governmental authorities for public procurement purposes.

While it may not interact with platforms and consortiums, it is the subject of governmental studies, and has been included in other studies lead by policy support institutions (e.g., OECD, 1997a). It also follows the definition of ISO 14024 standard on ecolabels (a framing Institution).

Sources: Eco Mark website. Available at: http://www.ecomark.jp/english/index.html; Capozza, I. (2011), "Greening Growth in Japan", OECD Environment Working Papers, No. 28, OECD Publishing, Paris. http://dx.doi.org/10.1787/5kggc0rpw55I-en ; OECD (1997a), "Eco-labelling: Actual effects of selected programmes", OECD, Paris, France.

Despite its simplifications, this static representation of the landscape of actors gives an apercu of the complexity of dynamic institutional interactions evolving around ELIS. A diversified range of businesses, public agencies, non-profit organisations, and civil society groups contribute to one or more of the institutional efforts requested to collect, analyse, verify and promote environmental information about a product or service from a supplier to a user. Their role varies depending on the scheme and may change over time, but they all relate at least indirectly to the increased number of schemes. Some aim at harmonisation, others at strengthening clubs of schemes, some help users, others consider options to address the potential challenges of this growth.

This review also provides the context and prefigures the growing diversity of ELIS, which is discussed in the next section. 


\section{Characterisation of ELIS}

\subsection{The ISO typology}

Despite their broad scope and diversity, only a few typologies of ELIS have been developed and used. The most widely used typology relies on the series of ISO 14020 standards, which separates environmental labelling schemes into three types (ISO, 1999a, 1999b and 1999c).

- Type I (ISO 14024) is the standard for ecolabels, defined as multi-criteria, whole life-cycleapproach-based, third-party voluntary labelling schemes that distinguish some of the best performing products according to predetermined environmental criteria and apply to diverse product categories. These labels are designed to reward environmental excellence and, as such, are a market-based tool designed to encourage environmental improvement. Most ecolabels have been introduced by or with the contribution of government agencies, setting multi-criteria standards that have then been adopted on specific ranges of products starting in the late 1970s.

- Type II labels (ISO 14021) are self-declared claims, privately made, that describe a product based on one or more characteristics following general guiding principles. In particular they have to be verifiable, and use accurate and non-misleading information. The standard provides guidance as to the proper use of ubiquitous symbols and terms (e.g., "recyclable").

- $\quad$ Type III (ISO 14025) focuses on environmental declarations, providing quantitative indicators of environmental performance based on life-cycle assessments. These declarations are generally intended for businesses-to-business communication, but can be used by consumers provided they are third-party audited.

The specific characteristics of each type are shown in Table 2.

Table 2. ISO Standards and their main requirements

\begin{tabular}{|c|c|c|c|}
\hline $\begin{array}{c}\text { ISO } \\
\text { Standard }\end{array}$ & Type & Requirements & $\begin{array}{l}\text { Examples of } \\
\text { schemes }\end{array}$ \\
\hline 14024 & Type I - Ecolabels & $\begin{array}{l}\text { Multi-issues third-party voluntary labels } \\
\text { indicating high environmental performance } \\
\text { based on set of life-cycle-based criteria } \\
\text { and designed and implemented in a } \\
\text { transparent manner. }\end{array}$ & $\begin{array}{l}\text { Blue Angel, Nordic } \\
\text { Swan, Canadian } \\
\text { Environmental } \\
\text { Choice. }\end{array}$ \\
\hline 14021 & $\begin{array}{l}\text { Type II - Self-declared } \\
\text { Environmental Claims }\end{array}$ & $\begin{array}{l}\text { Private claims, first-party verified, adhering } \\
\text { to specific principles (verifiable, accurate } \\
\text { information, not misleading). }\end{array}$ & $\begin{array}{l}\text { Recycled content, } \\
\text { Biodegradable. }\end{array}$ \\
\hline 14025 & $\begin{array}{l}\text { Type III - } \\
\text { Environmental } \\
\text { Declarations }\end{array}$ & $\begin{array}{l}\text { Quantified environmental information, } \\
\text { based on life-cycle analysis, using } \\
\text { independent verifiable data, primarily used } \\
\text { for business-to-business communication. }\end{array}$ & $\begin{array}{l}\text { Eco-Leaf; Korean } \\
\text { Environmental } \\
\text { Declaration of } \\
\text { Products. }\end{array}$ \\
\hline
\end{tabular}

Sources: ISO (1999a; 1999b and 1999c); Allison and Carter (2000); GEN (2013); JEMAI (2013); KEITI (2013).

Despite its apparent wide coverage, and the importance it has in the literature, this typology fails to represent the full diversity of ELIS. In particular, some of the most widely used environmental labelling schemes on consumer products are certification schemes that are third-party audited but neither life-cycle based nor multi-criteria, such as organic certified products, the energy star label, or the multiple schemes 
whose organisations are member of the ISEAL Alliance. Third-party audited quantitative reporting schemes that are not life-cycle based, such as those relating to energy performance, or fuel efficiency, are also excluded from this typology. ISO has looked at additional 14000 standards covering some of these types of labels, but these efforts have not all been concluded.

\subsection{Towards a more comprehensive picture}

Databases set up by ELIS inventorying institutions have moved towards a more comprehensive representation of schemes, by including a larger set of criteria. Twelve key criteria they use, selected by their importance, and ordered thematically are listed in Table 3. Notwithstanding the simplified categorical responses enumerated in this table, abstracting from greater levels of detail reported by some of the inventories, these criteria provide a sufficiently broad set of elements to differentiate ELIS in a unique manner.

The selected criteria are grouped into two overarching classes related to the mode of communication and the characteristics of the scheme. First, four modes of communication are used to capture essential elements describing ELIS. They define the information provider and receiver (ELIS suppliers and users), the signal being communicated, the target of the communication, and the content of the information. Various communication channels are distinguished in the literature, but the most important tend to be business-to-consumers (labels) and business-to-business (schemes). Three main means of communication are suggested - seals, declaration and claims- with further extension possible, providing examples of the complexity of the message. Products and service categories and the environmental attributes are basic features that help differentiate ELIS. ELIS suppliers define most of these characteristics, but they adapt the modes of communication to the ELIS users they want to reach.

Second, eight criteria describe the standard characteristics to help identify the rule-setter and the scheme owner or leader and indicate the standard's governance, method, transparency, focus, and scope. The first characteristic reports the dichotomy among suppliers defined in Figure 1. The leadership and mode of governance are critical to understand the incentives behind the use of ELIS. ELIS suppliers are generally deciding these characteristics, but their decisions also depend on the guidelines, rules and regulations set by framing institutions, policy support institutions and potentially by the support groups or platforms to which they belong. A scheme's focus and scope may be intentionally designed or just descriptive characteristics that suppliers take as exogenous in their decisions.

The most important criteria for standard setters and outside informed observers include transparency, monitoring and the assessment method. The use of a life-cycle approach (LCA) ${ }^{9}$ has significant implications. ELIS that use LCA try to incorporate a wider types of impact of a product, therefore reducing the risk of one sided environmental characteristics. Transparency and verification procedures also matter greatly, as they affect the credibility of the scheme and its readability from outside observers. How much information is available is a gauge of trust. Third-party auditing is considered a necessary means to be credible, as it help ensure an independent verification of environmental claims.

A life-cycle approach (as referred to in ISO Standard 14024) does not imply the use of life-cycle assessment (ISO 14021). In the first case, the analysis of environmental performance is undertaken at different stages in the life cycle of the product, while in the second case, a quantified assessment is performed to provide systemic estimates of environmental impact of a product over its whole life cycle. 
ENV/WKP(2013)9

Table 3. Main characteristics of ELIS

\begin{tabular}{|c|c|c|}
\hline Type of criteria & Categorical responses & Examples \\
\hline \multicolumn{3}{|l|}{ Modes of Communication } \\
\hline Communication channel & $\begin{array}{l}\text { Business-to-business (B2B), } \\
\text { Business-to-consumer (B2C), } \\
\text { Business-to-government (B2G), } \\
\text { Government-to-consumer (G2C) }\end{array}$ & $\begin{array}{l}\text { B2B: Abengoa RED; B2C: Krav Organic; } \\
\text { G2C: Eco Mark Japan. }\end{array}$ \\
\hline Means of communication & $\begin{array}{l}\text { Seal, report or declarations. } \\
\text { That can be further decomposed into } \\
\text { ISO types and exceptions: organic, } \\
\text { other single-issue label, resource } \\
\text { efficiency label. }\end{array}$ & $\begin{array}{l}\text { Seal: Types I ecolabels } \\
\text { Declarations: Type III labels }\end{array}$ \\
\hline $\begin{array}{l}\text { Communication scope: } \\
\text { category of good or service } \\
\text { targeted }\end{array}$ & $\begin{array}{l}\text { Agriculture and food, textile } \\
\text { products, forest products, buildings } \\
\text { and furniture, energy, transportation, } \\
\text { biofuels, tourism, household } \\
\text { appliances, electronics, cosmetics, } \\
\text { cleaning products. }\end{array}$ & $\begin{array}{l}\text { Agriculture and Food: Protected Harvest; } \\
\text { Textile: Oeko Tex Standard 100; Forest } \\
\text { products: Forest Stewardship Council; } \\
\text { biofuels: 2Bsvs; Tourism: Blue Flag; } \\
\text { Appliances: Top Runner Program. }\end{array}$ \\
\hline $\begin{array}{l}\text { Communication content: } \\
\text { Environmental attributes }\end{array}$ & $\begin{array}{l}\text { Natural resource, energy, sources of } \\
\text { pollution (chemicals), biodiversity, } \\
\text { climate, waste, other, multiple }\end{array}$ & $\begin{array}{l}\text { Natural resource: Water Stewardship; } \\
\text { Energy: Energy Star; Biodiversity: Shade } \\
\text { Grown Coffee; Climate: Carbon Labels.org; } \\
\text { Waste: Biodegradable. }\end{array}$ \\
\hline \multicolumn{3}{|l|}{ Standard Characteristics } \\
\hline Standard setter & $\begin{array}{l}\text { Self-setting } \\
\text { External certifier }\end{array}$ & $\begin{array}{l}\text { Type II ELIS: self-claims; ISEAL Alliance } \\
\text { members: external certifiers }\end{array}$ \\
\hline Leadership or ownership & Private, public, non-profit, hybrid & $\begin{array}{l}\text { Private: Casino Carbon Index; Public: } \\
\text { Korean Carbon footprint label; Non-profit: } \\
\text { Friend of the Sea; hybrid: Roundtable on } \\
\text { Sustainable Soy Association }\end{array}$ \\
\hline Mode of governance & Voluntary versus mandatory & $\begin{array}{l}\text { Voluntary: UL Environment } \\
\text { Mandatory: EnerGuide. }\end{array}$ \\
\hline Transparency & $\begin{array}{l}\text { Availability of information on the } \\
\text { standard setting process (yes or no), } \\
\text { publication of awardees (yes or no). }\end{array}$ & $\begin{array}{l}\text { Open: EU Ecolabel } \\
\text { Not: Bonsucro }\end{array}$ \\
\hline $\begin{array}{l}\text { Methods for environmental } \\
\text { assessment }\end{array}$ & $\begin{array}{l}\text { Life-cycle approach (LCA) based or } \\
\text { not }\end{array}$ & $\begin{array}{l}\text { LCA based: Environmental Choice Canada } \\
\text { Non-LCA based: USDA National Organic } \\
\text { Program. }\end{array}$ \\
\hline Monitoring and auditing & First-party, second-party, third-party & $\begin{array}{l}\text { First-party: EPA SmartWay } \\
\text { Second-party: Green Seal } \\
\text { Third-party: Bio-Suisse }\end{array}$ \\
\hline Standard focus & $\begin{array}{l}\text { Product standard, prPPM, nprPPM, } \\
\text { service }\end{array}$ & $\begin{array}{l}\text { Product Standard: Energy efficiency labels } \\
\text { prPPM: Imprim'Vert } \\
\text { nprPPM: Timberland Green Index }\end{array}$ \\
\hline Standard scope & Regional, national, international & $\begin{array}{l}\text { Regional: Pure Catskills } \\
\text { National: Korean EcoLabel } \\
\text { International: Marine Stewardship Council }\end{array}$ \\
\hline
\end{tabular}

Sources: Author, with examples from Blackman et al. (2012); Capozza (2011); Earley and Anderson (2003); EPA (2013); EVEA et Savin Martinet Associés (2012); OECD (1994a; 1997a; 2005; 2007; 2009b, 2009c; 2011a and 2012); Mazur (2012); Moïsé and Steenblik (2011); and Ottman (2011).

With regards to international trade, a traditional differentiation separates information remedies into mandatory and voluntary measures, but also between public and private measures, and those that focus on a characteristic of the final product (called product standards in Table 3) from those that relate to the processes and production methods (PPMs) used to produce the good (OECD, 1997b). This last category can be further decomposed into product-related PPMs (prPPMs) and non-product related PPMs (nprPPMs), depending on whether the production method has a measurable impact on the final product or 
not. These distinctions, which define the possible responsibility of governments and indicate the distance between the environmental practices and the final good's physical characteristics, may matter in the use and interpretation of national and international trade rules (e.g., see UNEP and IISD, 2006; Motaal, 1999; OECD, 2003). In particular, the use of nprPPMs to differentiate products remains the subject of trade contention (e.g., Conrad, 2011; Low et al., 2011).

Box 2 provides two examples of how different ELIS can be characterised using the twelve criteria presented in Table 3. As shown in these examples, there are significant links between the different criteria. Generally speaking, three group of ELIS can be distinguished by their modes of communication, largely following the three suggested means of communication. On the one hand, a significant number of ELIS act as seals of recognition for goods that are relatively more environmentally friendly, representing simple signals of quality. Obtaining the seal may require sophisticated information about multiple environmental areas, but this information is synthesised into a simple format for immediate visibility and ultimately credibility and recognition (assuming a transparent processes and sufficient monitoring). These include ISO Type I and II labels and single-issue labels, such as organic products or paper certified by the Forestry Stewardship Council.

\section{Box 2. Characterising ELIS: two contrasting examples}

Organic certification schemes are among the first and most recognized environmental labels. Krav Organic, set up in 1985 in Sweden, is an example of such a certification system that enjoys broad national recognition. It shares its modes of communication with other organic certification systems; pursuing a B2C communication channel, using a seal as means, focusing on agriculture and food products and standing for a set of agricultural practices (in particular preventing the use of synthetic pesticides and fertilizers) with the goal of reducing agricultural pollution and promoting biodiversity conservation. Standards characteristics on the other hand may vary across organic certification programs. If it is a voluntary labeling system not based on a life-cycle approach, Krav uses external certifiers, is owned by a non-profit organization, and it has an open standard setting process, but does not publish awardees explicitly (except importers). It uses third-party monitoring, operates mostly at the national scope, and its standard could be categorized as nprPPM, as the practices it cover do not all directly affect the physical nature of the final product.

In contrast, the Global Green Tag is a private multi-criteria quantitative life-cycle assessment certification system mainly applied to buildings. It focuses on business-to-business communication, uses report and seal means of communication (with a scale of grades from bronze to platinum, plus a dual rating, depending on the performance). It focuses on buildings and covers multiple attributes, including biodiversity, greenhouse gas emissions, and toxicity. While it is privately owned and operating as a certifier, it follows ISO standards (including ISO 14024 type III labels), with a transparent standard-setting system (awardees and standards available) and provides a voluntary service, with second-party monitoring. It operates at the international level and incorporates methods that can fit the definition of nprPPMs.

Sources: Krav website, www.krav.se/english, accessed July 2013; Global Green Tag website, http://globalgreentag.com/, accessed July 2013

On the other hand, ELIS relying on complex reporting methods, which are typically closer to environmental audits displaying quantitative characteristics of products or services, require more time for users to understand. Environment Product Declarations and Type III schemes belong to this group. They may be used for services, to rate companies, or to depict the environmental footprints of goods. They are also used for long-term purchases, as observed for instance with energy- or fuel-efficiency-related information schemes applied to cars and appliances in a number of countries. The credibility of these schemes relies in part in the completeness of their methods and reporting option. Naturally, the environmental attribute they focus on have to be measurable quantitatively, which is not always trivial (e.g., effects on biodiversity). This group of ELIS is also more suitable for environmental attributes where directions of quantified indicators are easy to understand by users (more is bad or more is better). 
Examples include the Korean Environmental Declaration Program, set up by the Korean government as a voluntary program for companies to assess their environmental performance under selected and measurable criteria.

Lastly, a third set of schemes lies in-between these two groups, looking at quantitative factors, presented in a simpler ordered way, or mixed quantitative-qualitative modes of communication. This can be done either via the use of an ordered scale embedded into the seal, whereby products or services can be rated at discrete levels of performance (stars or gold and diamond ratings), or via a visible scale, with numbers of colour codes (traffic light), that can be multi-criteria. The Global Green Tag (Box 2) uses such a system. The intention is to catch the eye of the users, and yet enable a more advanced categorisation than a binary ( 0 or 1$)$ seal. Naturally, some type of quantification is necessary.

More complex interactions are observed when considering the characteristics of the standards defining the schemes. Self-set standards are often privately driven, voluntary, and first- or second- party audited. Many follow the "private" route in Figure 1, but they can use any mode of communication. Externally certified programmes, which follow the other route, largely vary in terms of the other criteria and even modes of communication. Public, non-profit and hybrid-led schemes are not as simple to associate with other criteria. Mandatory schemes remain an exception in ELIS, as they apply only to specific sets of goods and attributes, and aim to reach standardised information disclosure. The focus and scope are directly related to the environmental attribute and product or service category being considered.

As shown in Box 2, determining the characteristics of specific schemes as presented in Table 3 is relatively straightforward for most criteria in the list, because they are subject to a few mutually exclusive distinguishable categorical responses. However, a number of characteristics can be more difficult to determine, given the possible non-exclusive nature of the respective criteria. Several communication channels can be applied to a scheme: for instance, certain schemes applied to buildings could be considered both business-to-business (B2B) and business-to-consumer (B2C). The distinction between voluntary and mandatory schemes may also be subject to nuances; some of the ELIS may be voluntary governed but based on mandatory measurement or calculation methods, such as governmentally regulated schemes. Voluntary ELIS can also be considered "de facto mandatory" if they are taken up by a major market player or by a majority of players in a market forcing their suppliers to comply or exit the market. Transparency may also need much more detailed information about not only the standard but the governing mechanism of specific schemes. These seemingly minor distinctions, not listed in Table 3 for simplification, may matter when comparing schemes in detail or considering their relative impact.

Another exception is associated with standard ownership. In recent years, governments and non-profit organisations have been increasingly indirectly involved in joint-ventures with private schemes, creating a blurred landscape of schemes (OECD, 2011a). Recently launched roundtable certification schemes (such as the Roundtable on Sustainable Palm Oil and the Roundtable for Sustainable Biofuels), for instance, rely on partnerships between different actors of the public and private sectors. In such framework, the main actors are invited to the table; contribute to the discussion and to the setting of a standard that is then given for management to a separate secretariat. In other cases, standards were publically set, but implemented by private actors.

More generally, the role of public authorities has become multifaceted and difficult to apprehend (e.g., ITC, 2012). On the side of ELIS suppliers, governments have acted beyond their responsibility on mandatory regulations as standard-setters and leaders, certifiers and promoters. On the side of users, they have supported the use of schemes directly via green public procurement measures (e.g., Capozza, 2011), or indirectly by promoting the use of specific schemes in meeting regulatory requirements (Moïsé and Steenblik, 2011). They can also promote the use of ELIS via awareness campaigns and education programmes on a specific issue. Lastly, they can act by linking with one or more of the five institutional 
groups identified in Figure 2: providing funding and promoting specific groups, funding inventories and consumer guidance efforts, regulating claims and labels, and interacting directly with platforms and policy supporting institutional actors.

Table 4 lists twenty-four roles they may have and lists observed examples in OECD countries. The list may not be exhaustive, but it contains some of the perhaps more common roles observed internationally. Naturally, a specific national government will likely be involved in a few (if any) of these roles, rather than the entire list, but there may be also independent and unrelated contributions from different governmental agencies in a number of different roles.

Some of the listed roles may have implications in terms of international trade. In particular, a government's direct involvement in a scheme, as an ELIS supplier or user, or the regulatory measures it may take as a framing institution, may be subject to international contention. Further investigation could be useful to determine whether activities of a government are consistent in objectives, or whether they amplify or deter the multiplication of schemes. ${ }^{10}$

The following section uses this characterisation to examine the evolving characteristics of an international set of ELIS.

Table 4. Observed roles of government

\begin{tabular}{|c|c|c|}
\hline Institutional role & Identified specific role & Observed examples in OECD countries \\
\hline As ELIS supplier & $\begin{array}{l}\text { 1. Setting Standard } \\
\text { 2. Managing Standard } \\
\text { 3. Certification } \\
\text { 4. Promotion }\end{array}$ & $\begin{array}{l}\text { Public ELIS examples } \\
\text { Type I labels }\end{array}$ \\
\hline As ELIS user & $\begin{array}{l}\text { 5. Public procurement } \\
\text { 6. Regulatory fulfilment }\end{array}$ & $\begin{array}{l}\text { EU procurement program } \\
\text { EU biofuel directive }\end{array}$ \\
\hline $\begin{array}{l}\text { With supporting } \\
\text { institutions }\end{array}$ & $\begin{array}{l}\text { 7. Member of group } \\
\text { 8. Contributing to activities of the group } \\
\text { 9. Funding activities of the group } \\
\text { 10. General awareness and education }\end{array}$ & $\begin{array}{l}\text { GEN membership, } \\
\text { Mutual recognition of organic schemes, } \\
\text { Agencies funding IFOAM. } \\
\text { General consumer education programs }\end{array}$ \\
\hline $\begin{array}{l}\text { With inventorying } \\
\text { institutions }\end{array}$ & $\begin{array}{l}\text { 11. Lead public inventory } \\
\text { 12. Promoting inventories and guides } \\
\text { 13. Funding activities }\end{array}$ & $\begin{array}{l}\text { Danish guidance forbrug.dk } \\
\text { Support of ITC Standard Map, Ecolabel.be in } \\
\text { Belgium. }\end{array}$ \\
\hline $\begin{array}{l}\text { With policy } \\
\text { support } \\
\text { institutions }\end{array}$ & $\begin{array}{l}\text { 14. As part of international organisations } \\
\text { 15. Leading analysis or dialogue internally } \\
\text { 16. Funding analysis or dialogue externally } \\
\text { 17. Funding academic research }\end{array}$ & $\begin{array}{l}\text { UNFSS, OECD, others } \\
\text { Ademe (France) } \\
\text { ENTWINED ( Sweden), PEF project (Germany) } \\
\text { EU Research Frameworks, }\end{array}$ \\
\hline $\begin{array}{l}\text { With platforms } \\
\text { and consortiums }\end{array}$ & $\begin{array}{l}\text { 18. Member of a platform } \\
\text { 19. Funding a platform }\end{array}$ & $\begin{array}{l}\text { Product Sustainability Forum (UK) } \\
\text { Global Report Initiative (IADB) }\end{array}$ \\
\hline $\begin{array}{l}\text { As framing } \\
\text { institutions }\end{array}$ & $\begin{array}{l}\text { 20. Regulating and guiding claims } \\
\text { 21. Regulating labels or information } \\
\text { systems } \\
\text { 22. Obligatory disclosure } \\
\text { 23. Contributing to international guidelines } \\
\text { and standard-setting } \\
\text { 24. Actors in a trade dispute }\end{array}$ & $\begin{array}{l}\text { US Green Codes, France's practical guide on } \\
\text { environmental claims } \\
\text { EU Energy label, Korea's Carbon footprint label, } \\
\text { France (Grenelle } 1 \text { et } 2 \text { laws) } \\
\text { Canada's EnerGuide } \\
\text { ISO members, Contribution to FAO and ITTO } \\
\text { guidelines } \\
\text { US and Mexico: Dolphin-Tuna WTO disputes }\end{array}$ \\
\hline
\end{tabular}

Source: Author.

Acronyms: FAO: Food and Agriculture Organization. ITTO: International Tropical Timber Organization; PEF: Product Environmental Footprinting; IADB: Inter-American Development Bank. interactions for agro-environmental trade standards (OECD 2013). 


\section{Analysis of the growth in the number of ELIS}

The multiplication of ELIS has been observed since the 1990s (e.g., OECD, 1997a; Ceci-Renaud and Thao Khamsing, 2012; European Commission, 2012). However, the scope and characteristics of this growth have not been discussed in detail. While the number of programmes and initiatives is a good indicator of the increased fragmentation, the type of labelling scheme matters, especially when considering the potential impact of this multiplication on their effectiveness.

In this section, an empirical analysis is used to break down the growth by the characteristics identified in the previous section. To do so, a dataset of qualitative information based on the 435 programs in 197 countries managed by the EcoLabel Index (BigRoom, 2013), updated as of April 2013, is exploited. It is combined with the addition of schemes reported in recent publications and OECD reports ${ }^{11}$ treating of environmental labelling with sufficiently well-covered information. ${ }^{12}$ The resulting dataset includes 544 programmes introduced between 1970 and 2012. ${ }^{13}$ Despite its relative comprehensiveness, this database is not meant to be fully representative of the landscape of schemes as of 2012, and could present significant caveats. In particular, the EcoLabel Index may not include all the more recently introduced schemes. It likely provides a more comprehensive coverage of English language information, thereby creating a possible bias on those introduced in non-Anglophone countries. And it also focuses mostly on labels. Still, given its scope and diversity, the complementary additions from OECD reports and publications, and considering that small and less visible schemes are less significant for users, the combined dataset likely provides a sufficiently wide basis to draw lessons on the main features of the growth of ELIS operating in most OECD countries.

The EcoLabel Index repertories programmes, listing detailed information about their communication modes and standards, based on the responses of ELIS suppliers to a survey of 50 main questions, divided into 75 mostly qualitative detailed questions. For the purpose of the analysis, responses to selected questions in the survey are translated into 54 indicator variables taking the value 1 or 0 in the presence or absence of specific characteristics. These variables are listed in Table 5 with their aggregate values. ELIS are then ordered by year of introduction and the variables are aggregated annually, to provide a time series of the number of ELIS according to the selected criteria. Because some of the characteristics include multiple possible responses (environmental area or product categories), proportional adjustments are done to avoid over-counting and to ensure that the shares of programmes with the relevant attributes can be computed.

Table 5 outlines the diversity in ELIS. Schemes covered by the combined dataset cover multiple communication modes and standards in an uneven fashion. All categories listed have at least a few schemes and some include a very large number of schemes. The average of the sum in indicator variables is 133 , or just under a fourth of all schemes, but the standard deviation is 114, denoting the database's diversity. While most listed schemes originate from OECD countries in Europe and North America, 124 schemes come from other regions, including 66 introduced in non-OECD countries.

$11 \quad$ The following references have been used: Beltramello (2012); Capozza (2011); Chang (2012); Earley and Anderson (2003); EVEA et Savin Martinet Associés (2012); Global Fuel Economy Initiative (2013); Kang et al. (2012); OECD (1976; 1994a; 1994b; 1997a; 2009b; 2009c; 2012); Mazur (2012); Moïsé and Steenblik (2011) and PCF Projekt (2009a and 2009b). In the rest of the report the combination of these sources with the EcoLabel Index will be referenced as the combined dataset.

12 The selected OECD publications were identified based on a comprehensive internal review of all OECD publications treating at least partially of environmental labelling and information schemes from 1969 to 2013. Other publications were selected because they provide information on recent schemes not included in the EcoLabel Index database.

The three programmes initiated before 1970s and after 2012 were left out of the analysis. 
Table 5. Explanatory variables extracted from the combined ELIS dataset

\begin{tabular}{|c|c|c|c|}
\hline & & Indicator Variable & Sum \\
\hline \multirow{27}{*}{$\begin{array}{l}\text { Communication } \\
\text { modes }\end{array}$} & Communication channel & B2C communication channel & 381 \\
\hline & & G2C communication channel & 94 \\
\hline & & B2B communication channel & 62 \\
\hline & & G2B communication channel & \\
\hline & Communication means & ISO Type I ecolabel & 34 \\
\hline & & Organic Label & 81 \\
\hline & & Other single-issue label & 222 \\
\hline & & ISO Type II claim & 44 \\
\hline & & ISO Type III declaration & 26 \\
\hline & & Resource Efficiency & 25 \\
\hline & & Other communication mean & 112 \\
\hline & Communication target & Food and agriculture products & 139 \\
\hline & & Textile and forest products & 83 \\
\hline & & Buildings and furniture & 88 \\
\hline & & Energy, transportation, biofuels & 73 \\
\hline & & Tourism, financial & 30 \\
\hline & & Appliances, electronics & 42 \\
\hline & & Consumer, cosmetics, cleaning products & 26 \\
\hline & & Multiple products & 113 \\
\hline & & Other products & 25 \\
\hline & Communication content & Chemical control & 352 \\
\hline & & Natural Resource management & 339 \\
\hline & & Waste and recycling & 228 \\
\hline & & Energy efficiency & 200 \\
\hline & & Climate change mitigation & 193 \\
\hline & & Biodiversity conservation & 189 \\
\hline & & Other environmental areas & 167 \\
\hline \multirow{27}{*}{$\begin{array}{l}\text { Standards } \\
\text { Characteristics }\end{array}$} & Owner and mode of governance & Public mandatory & 21 \\
\hline & & Public voluntary & 80 \\
\hline & & Non-profit voluntary & 266 \\
\hline & & Hybrid voluntary & 17 \\
\hline & & Private voluntary & 160 \\
\hline & Transparency* & Open standard setting process & 176 \\
\hline & & Non-open process & 302 \\
\hline & & Awardees published & 259 \\
\hline & Monitoring* & First-party (audited or verified) & 28 \\
\hline & & Second-party (audited of verified) & 100 \\
\hline & & Third-party (audited or verified) & 231 \\
\hline & Method of assessment & LCA & 94 \\
\hline & & Non-LCA & 450 \\
\hline & Standard focus & Product Standard & 66 \\
\hline & & prPPM & 61 \\
\hline & & nprPPM & 334 \\
\hline & & Service & 83 \\
\hline & Region of origin & Europe OECD & 215 \\
\hline & & North America OECD & 205 \\
\hline & & Oceania OECD & 38 \\
\hline & & Asia OECD & 18 \\
\hline & & South America OECD & 2 \\
\hline & & Non-OECD & 66 \\
\hline & Scope & Sub-national scope & 12 \\
\hline & & National scope & 353 \\
\hline & & Regional scope & 76 \\
\hline & & International scope & 103 \\
\hline
\end{tabular}

\footnotetext{
Source: Derived from the combined dataset.
}

${ }^{*}$ Note: Transparency and monitoring variables are not available for all ELIS. There is no data on the openness of the standard process for 66 schemes, on the publication of awardees for 278 schemes, on auditing for 312 schemes and on verification for 151 schemes. 


\subsection{General trends}

Figure 3 provides an overview of the cumulative growth in ELIS between 1970 and 2012. The upper panel shows the evolution in the total number of schemes, with limited numbers until the mid-1980s, then a rapid growth from around 1988 to 2009 - multiplying the total number by five - and the reaching of a plateau in 2010-2012. The lower panel shows the annual growth in the number of schemes, further decomposing the time series into periods of growth. Four periods stand out in their acceleration of ELIS introduction: 1990-92, 1997, 2001-02 and 2007-08. These figures support the claim of a significant increase in the number of ELIS over time, but they also seem to indicate a possible slowing in growth in the past few years.

Figure 3. Evolution in the number of ELIS, from 1970-2012.

Upper panel: total number of schemes. Lower panel: new programmes per year.

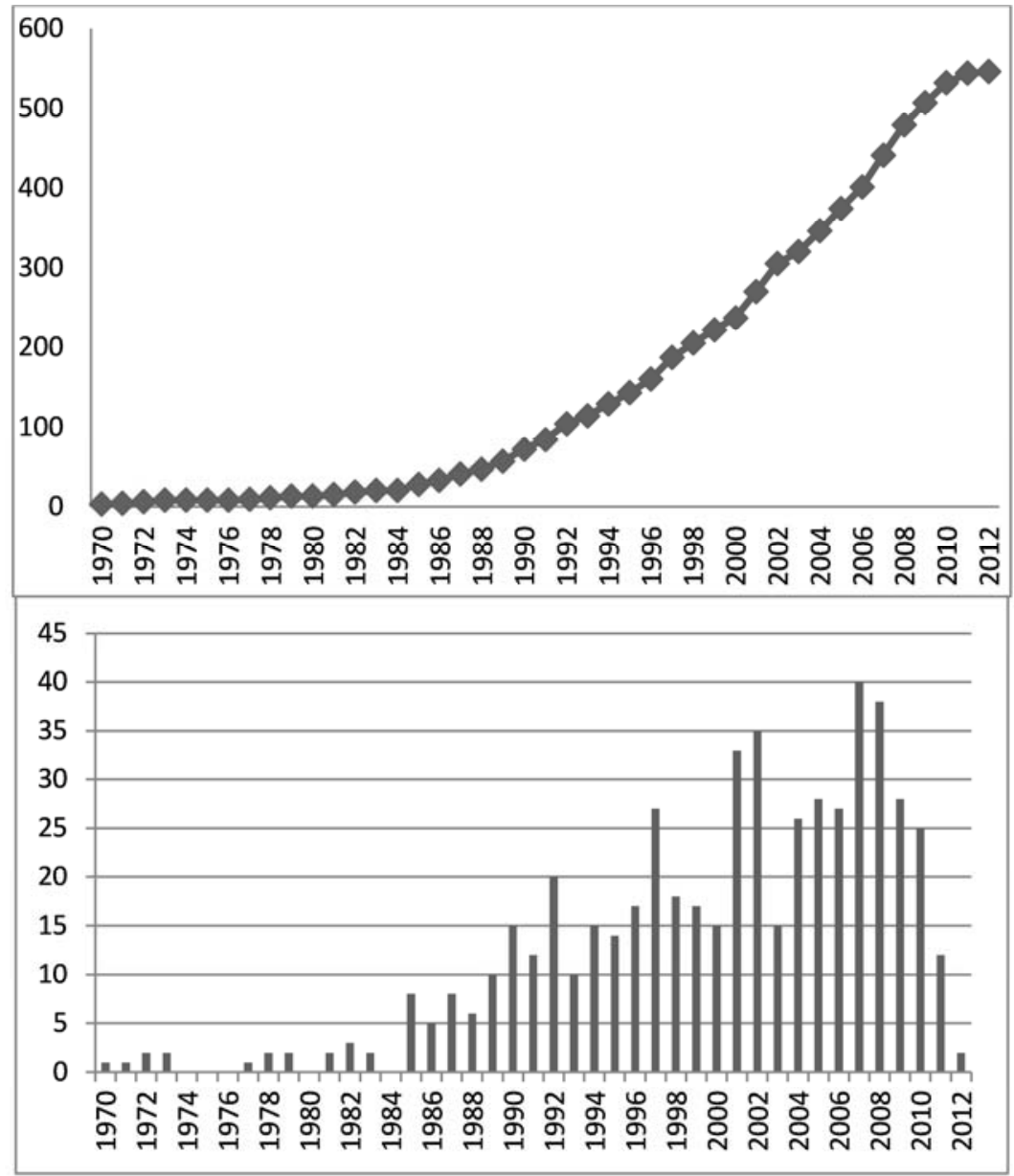

Source: Derived from the combined dataset.

Part of this slower growth may be solely due to the fact that the dataset used may not have recorded all the most recent schemes. To verify this hypothesis, a parallel analysis was conducted on trends in relevant registered trademarks. Trademarks containing the words "green", "sustainable", and "natural" were researched in official databases set by patent offices in selected OECD countries. These words were picked for their frequent use in ELIS and environmental programmes. In this setting, the number of trademarks may not provide a perfect representation of ELIS; trademarks include all new ELIS containing 
the relevant word, but also other programmes, institutions and brands. For the words "green" and "natural", the list may include the name of products that may not have any environmental significance (e.g., green paintings). Still, assuming that annual introductions of these non-environmentally connoted trademarks are relatively stable over time ("green" is a colour and "natural" existed before environmentally friendly products), if the trademark number demonstrates a similar growth slowing down overtime, it may confirm that ELIS are also slowing.

The results of this analysis are detailed in the Annex. They show that the number of registered trademarks with the words "green" and "sustainable" in all the selected OECD countries has in fact experienced a significant growth especially between 2005 and 2010, in parallel to the largest increase in ELIS observed in Figure 3. They also follow a pattern of slowing growth starting in 2010. Because patent registers provide data for the last three years, unlike the combined dataset we use, these results provide a partial confirmation of the observed reduced growth in ELIS. ${ }^{14}$ The confirmation is incomplete because these are only imperfectly representative variables but also because trademarks with the word "natural" do not experience the same pattern overall, perhaps because this word may have different uses in different countries (see Annex).

Of course, the growth in ELIS, even if slowing down, does not mask the impressive total number of schemes. But it is insufficient to know whether competition increased in the same segments or due to the multiplication and increased diversification of completely different schemes. To do so requires delving into the list of criteria listed in Table 3 and modelled in the variables presented in Table 5.

\subsection{Breakdown of growth by selected criteria}

Figure 4. Evolution of the number of ELIS by main communication channels

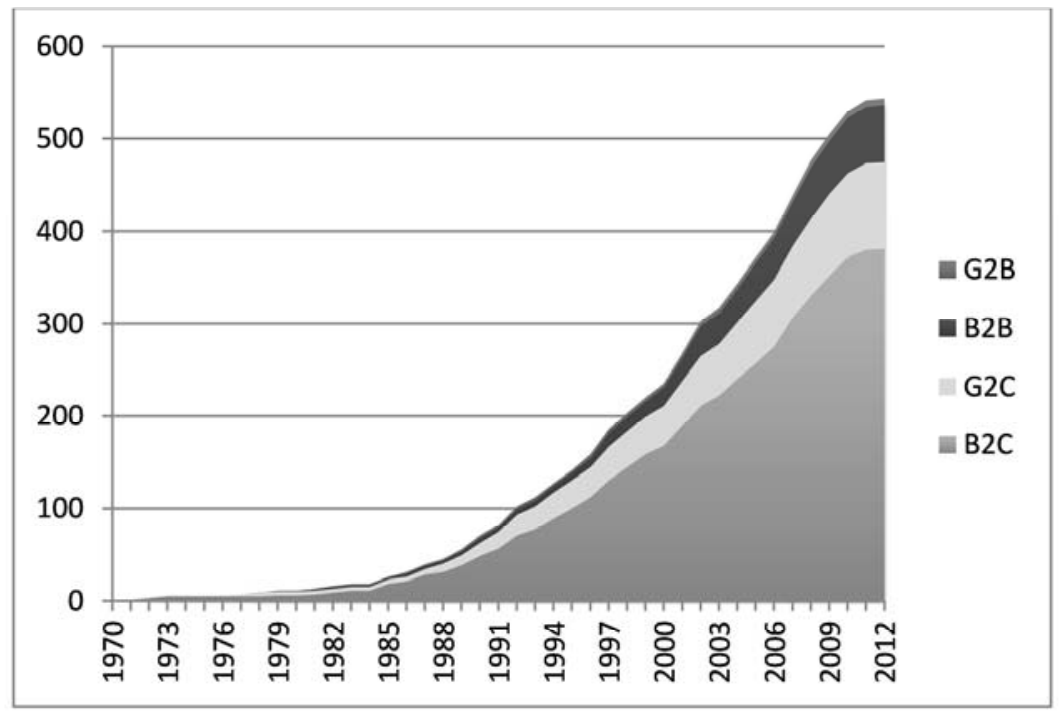

Source: Derived from the combined dataset.

Figure 4 uses the detailed dataset to decompose the growth by communication channels, focusing on business-to-consumers (B2C), government-to-consumers (G2C), business-to-business (B2B), and government-to-business (G2B) communications. B2C schemes occupy the largest share (70\%), and display the highest growth of the four channels, followed by G2C (17\%) and the two others (11\% and 1\%). Annual

14 If ELIS were continuing to grow at a faster rate in this period, this acceleration should be visible on trademark data at least in the main regions with ELIS. 
growth data also indicate that the number of $\mathrm{G} 2 \mathrm{C}$ schemes increased almost uniformly, whereas the number of B2C fluctuates largely with the total number of rates, as observed in the lower panel of Figure 3. This evolution suggests that businesses have been the main drivers of adoption of new schemes.

Figure 5 presents the evolution in means of communication. The upper panel shows the growth in four aggregate categories of ELIS: seals, claims, declarations, and others, during five periods within the fortytwo year time series. While environmental seals are the most widely introduced ELIS, are increasingly introduced over time, and develop at an accelerating rate in the early 2000s, the same evolution is not observed for the three other categories. Claims, declarations and other means follow a slowing growth until the end of the 1990s, and then a progressive acceleration in the first decade of 2000s.

Figure 5. Evolution of ELIS numbers by communication means

Upper panel: growth in seals, claims, declaration and others during five periods between 1970 and 2012. Lower panel figures: shares of ELIS by communication mean in 1990 (left) and 2012 (right).

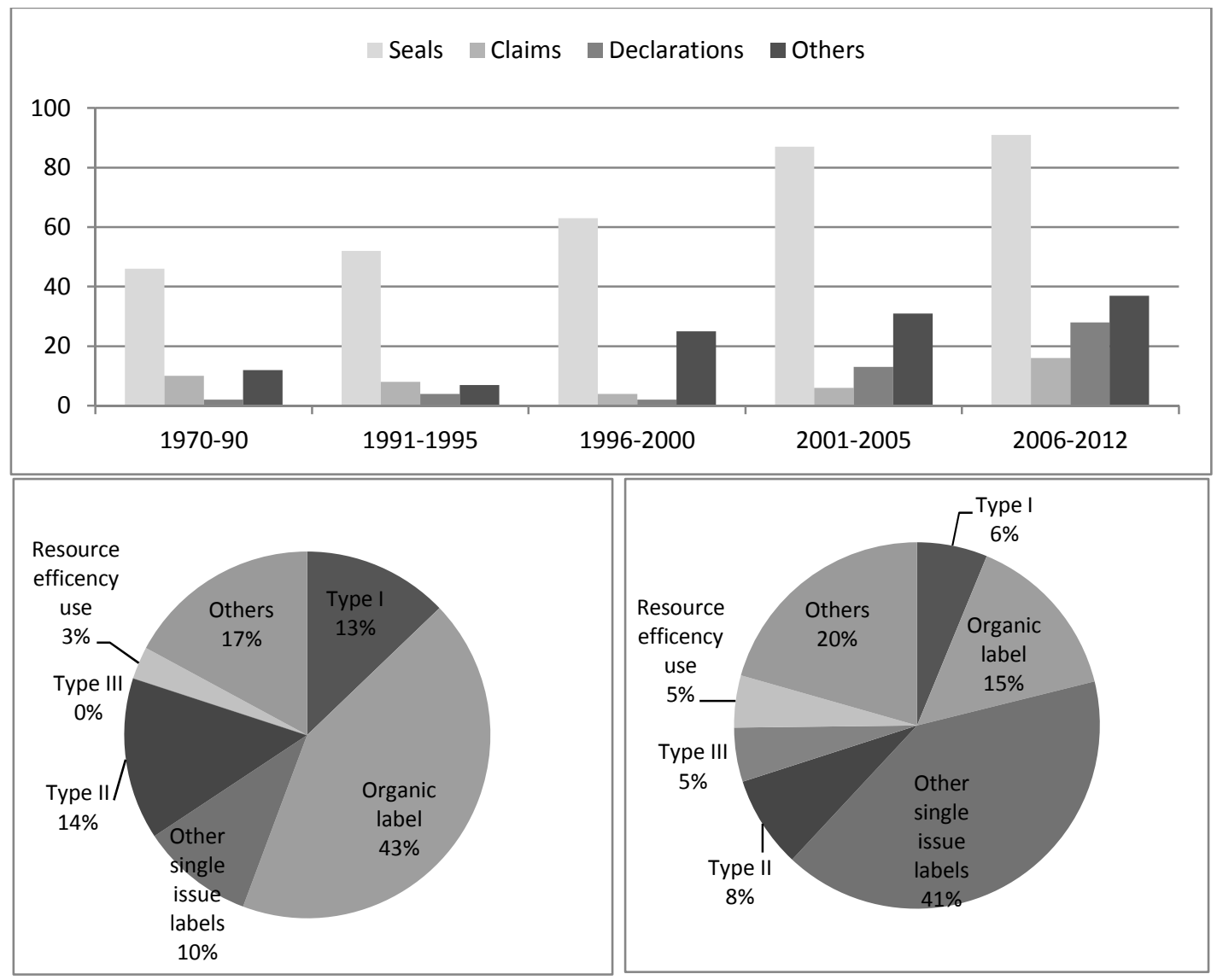

Source: Derived from the combined dataset.

The two lower panels in Figure 5 compare the shares of ELIS by communication means in 1990 versus 2012, further separated into ISO types, and other significant means (organic labels, other singleissue labels, and resource efficiency use schemes). In 1990, organic schemes, type II and type I labels were the dominant categories, representing $70 \%$ of the total number of ELIS in the dataset. Yet, with a slower increase in these categories relative to that of others, they only represented $29 \%$ of schemes in 2012. Instead, other single-issue labels became the dominant communication mean of ELIS (41\%) with other means, organic, and type II following. This demonstrates a clear shift in the nature of ELIS introduced over time. Organic certification and type I ecolabels were among the first types of schemes introduced until the 
early 1990s. The growth in ELIS in the two following decades was largely generated by the introduction of new certified environmental seals and claims. At the same time, type III and resource-efficiency categories also grew significantly in relative terms. Meanwhile, even with the increase of other schemes, the share of organic labelling schemes remains significant, pointing to the continued requested efforts to pursue harmonisation.

Figure 6. Evolution of ELIS numbers by communication scopes

Upper panel: Total number of ELIS by product category, 1970-2012. Lower panel: Introduction of ELIS by product category in five time periods, 1970-2012.

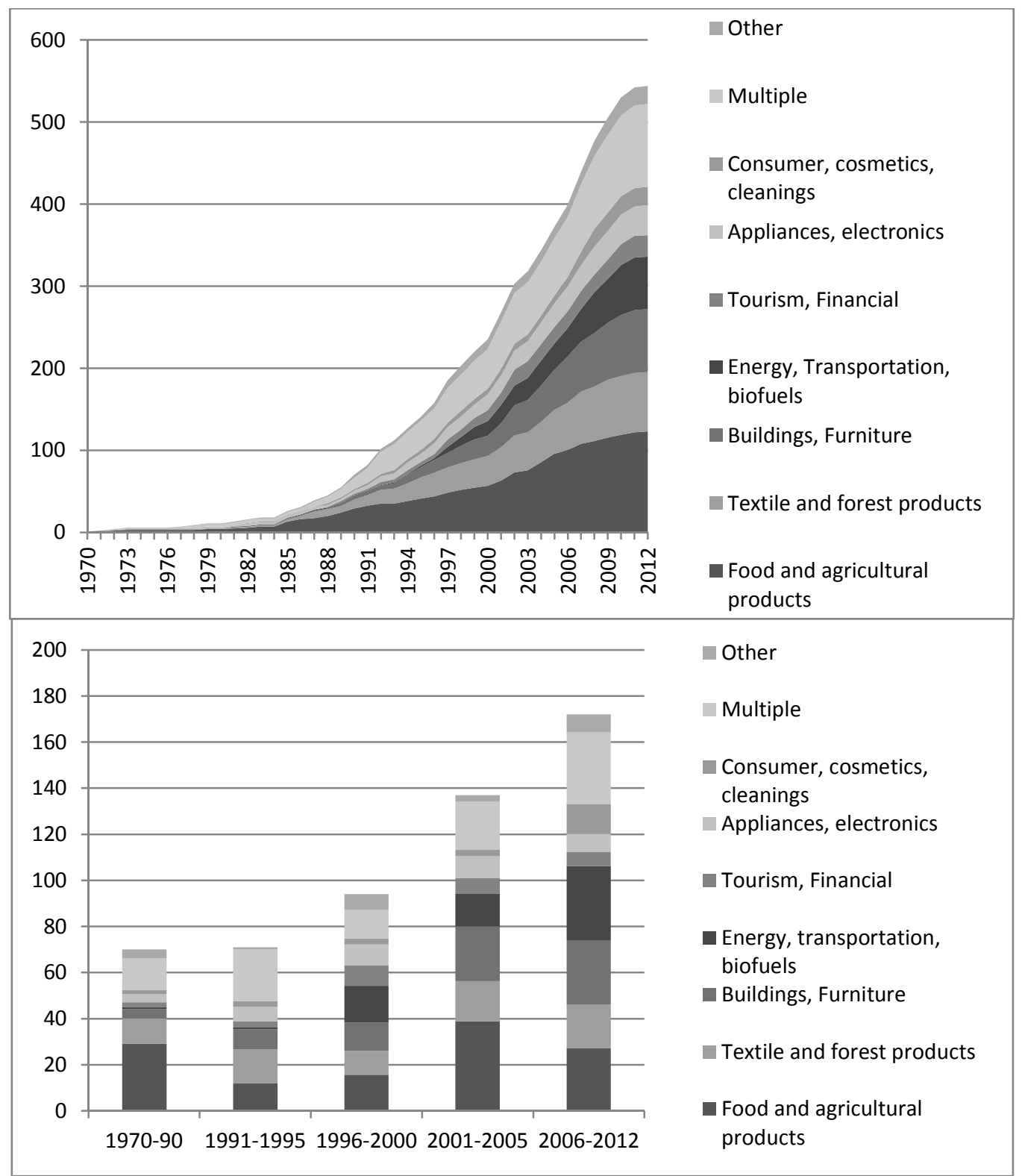

Source: Derived from the combined dataset.

Figure 6 further looks into communication modes by differentiating categories of products targeted by ELIS over time (defined as communication scope in Table 3). Unlike the previous pattern, there is a seemingly relative uniform spread of growth in most categories of products. But if some of the traditional 
areas, such as food and agriculture products, textile and forestry products, buildings and pieces of furniture exhibit a relative slow growth while keeping a dominant share of the ELIS, others rapidly increase from a low basis such as ELIS with multiple categories of products and especially those related to energy and transportation. In 2006-12, the first category in terms of growth is related to transportation and energy. This evolution suggests a differential maturity of the ELIS market by types of products.

Figure 7 reviews the determinants of ELIS growth in terms of environment areas. The coverage of most environmental areas increases in a seemingly proportional manner, but the number of climate change related schemes significantly increases from 1995 to 2012. The lower panel dissects the shares of programmes in 1990 and 2012, showing the observed diversification in schemes over time. In 1990, most ELIS were directed towards addressing challenges pertaining to natural-resource management, chemical control and the conservation of biodiversity (representing over 72 per cent). In 2012, a much more equal division of areas is observed; natural resources and chemical controls still represent the most covered areas, but they are followed by waste and recycling management, climate change, and energy.

Figure 7. Evolution of ELIS numbers in communication content

Upper panel: Total number of ELIS by environmental focus area, from 1970 to 2012.

Lower panel: Shares of environmental area coverage in 1990 (left) and 2012 (right).

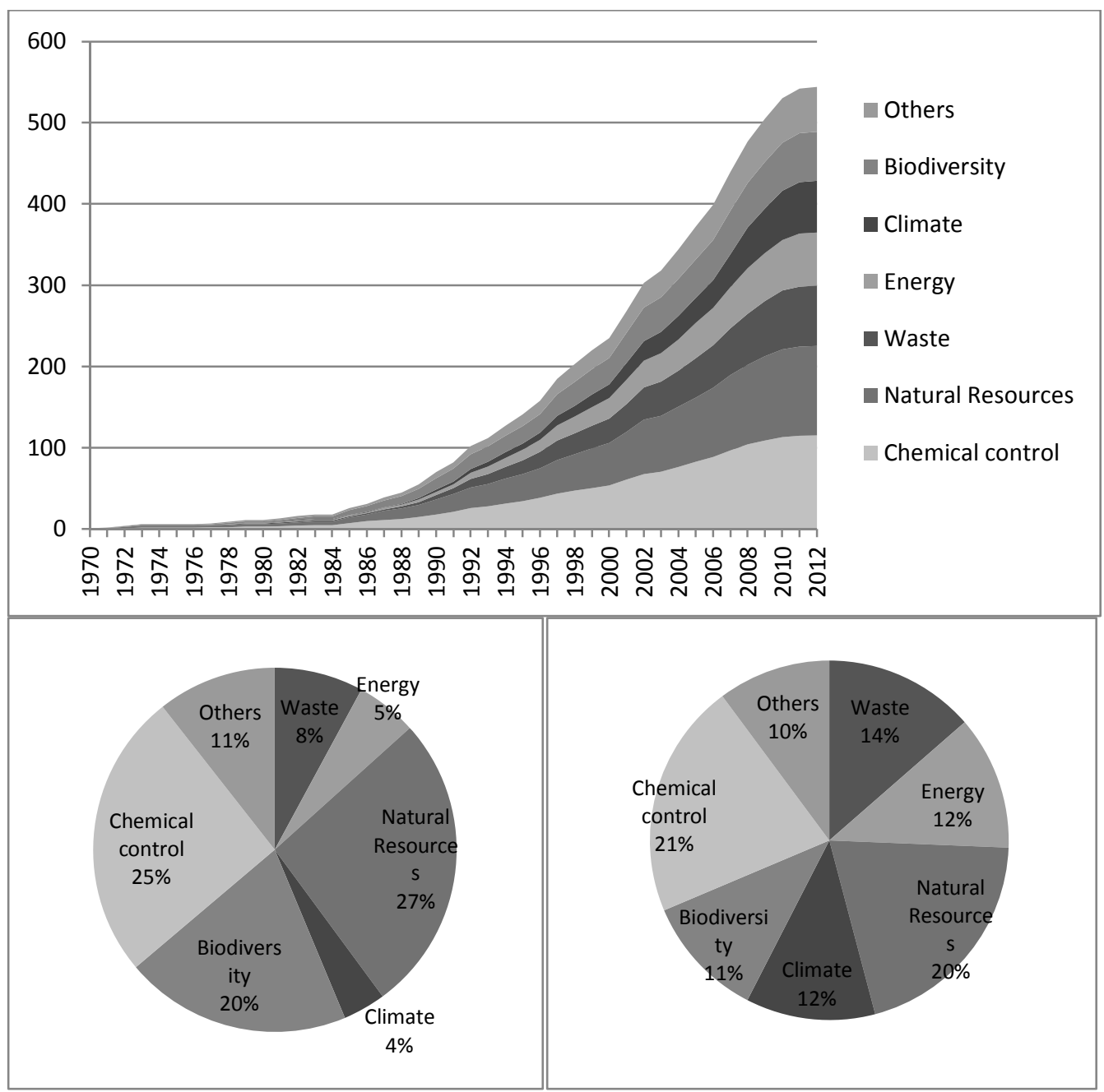

Source: Derived from the combined dataset. 
Turning to the characteristics of the standards, Figure 8 provides trends in ownership and modes of governance, methods, and focus. The upper panel shows that non-profit voluntary schemes largely dominate over time, but the number of private claims has also increased rapidly, faster than the number of public voluntary schemes. Other categories include much fewer schemes.

The middle panel focuses on transparency, combining an indicator variable standing for the openness in the standard-setting process and a second one outlining the presence or absence of a published list of awardees. The bottom area in this figure includes the most transparent schemes and the top category includes the least transparent. The evolution shows an increase in the four categories, with the majority of schemes being less transparent, and the largest group having neither open standard-setting process nor publishing an awardees' list. However, further examination of the data reveals that the relative proportion of transparent schemes has increased overtime. In 1990, 77\% of the schemes in this restricted dataset had an opaque standard setting process. This share decreased to $67 \%$ in 2012, with most of the increase in the category of open process and published awardees (from $21 \%$ to $32 \%$ of the total).

This trend suggests a partial and incomplete improvement in transparency of ELIS, despite significant efforts by virtually all the main identified institutional groups to promote transparency. Indeed, all major ELIS supporting institutions do emphasise the need to follow general principles of transparency. Most platforms and consortiums also outline transparency as a necessary step. Several of the inventorying institutions base their criteria for the use of specific ELIS on transparency. Policy support institutions promote transparency as a necessary condition for ELIS, and key framing institutions also support transparency principles. And yet, most schemes on this figure appear to remain opaque.

The lower panel confirms the presence of a partial amelioration in the credibility of new standards. The figure shows the domination and continued increase in third-party audited or verified ELIS ${ }^{15}$ among those with monitoring information during the covered period. The share of third-party audited schemes increased from $50 \%$ in 1990 to $64 \%$ in 2012 . At the same time, second-party audited or verified schemes increased significantly in 2000-2012.

15 The three main categories in this figure combine data from a variable on audit type and on verification. First-, second-, or third-party audited or verified schemes represent schemes that have been verified or audited or both by these parties; thereby excluding schemes that may have been audited by one type of party and verified by another. 
Figure 8. Evolution of the number of ELIS by standard characteristics

Upper panel: Total number of ELIS decomposed into modes of governance and ownership between 1970 and 2012. Middle panel: Transparency in standard setting process (open or not) and the publication of awardees. Lower panel: Introduction of ELIS by monitoring type in five time periods, 1970-2012.

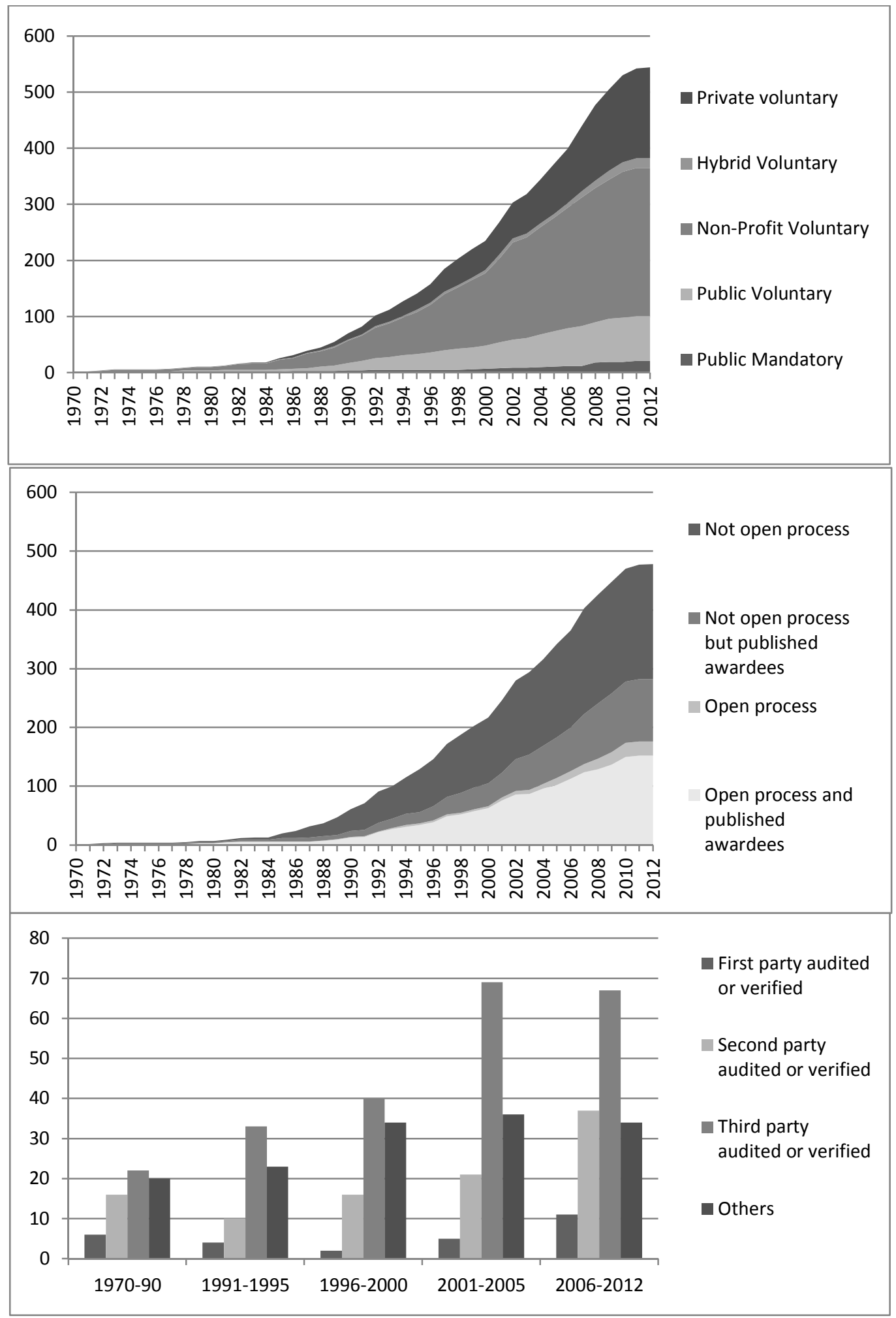

Source: Derived from the combined dataset.

Notes: The transparency figure (middle panel) only includes 478 ELIS, the monitoring figure includes only 359 ELIS. 
Figure 9. Evolution of ELIS by standard method and focus

Left panel: Total number of ELIS by standard method.

Right panel: Introduction of ELIS by standard focus in five time periods, 1970-2012.

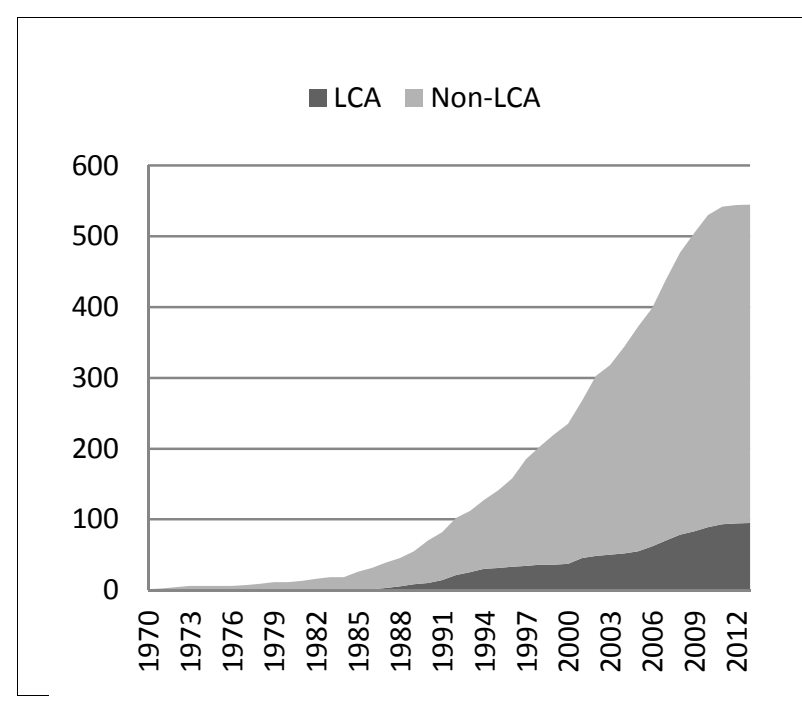

a Product standard $\square$ PrPPM $\square$ nprPPM $\square$ Service

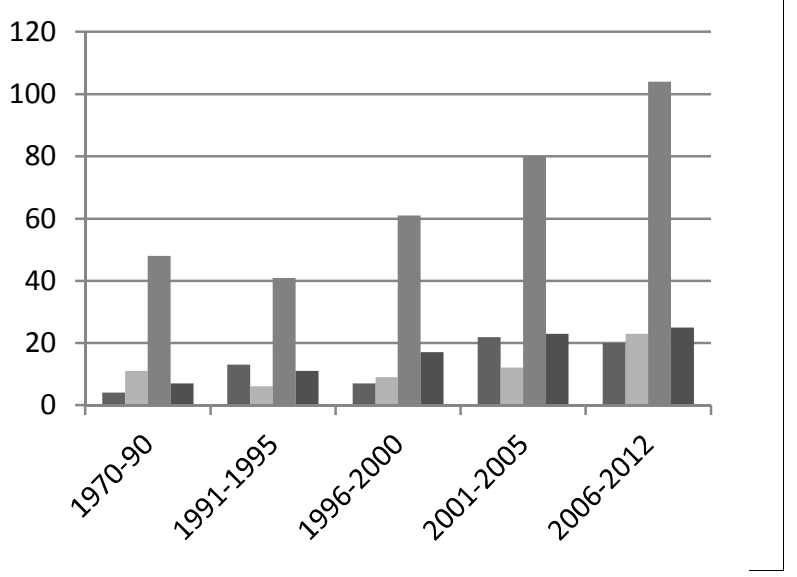

Source: Derived from the combined dataset.

Figure 9 shows the evolution in terms of standard method and focus. The left panel reveals that schemes based on life-cycle approach (LCA) methods represent a relatively stable minority of ELIS, and that most of the growth has been with non-LCA based schemes. The right panel shows the growth in the number of PPMs and services, decomposed into five periods. Product standards, the two types of PPMs and services have increased in the last four periods, but nprPPMs, which have been the most contentious in international trade discussions, have been increasing at a much faster rate than others.

Finally, Figure 10 looks at the standard scope by outlining the geographical dispersion in new schemes and their application over time. On the upper panel of the figure, OECD countries are grouped into continents, with non-OECD countries separated. Most schemes in the dataset have consistently been introduced in Europe and North America, followed by Oceania, Asia, non-OECD, and South America. As noted before, this distribution may be the result of biases in the database, which covers more comprehensively schemes with English information available. Still, non-OECD countries represent an increasing share of ELIS over the forty year period.

The evolution of the geographical scope of ELIS also reveals a similar pattern, with dominating categories, as shown in the lower panel of Figure 10. Most ELIS have been operating at the national level. The share of national ELIS has even increased from 59\% in 1990 to $65 \%$ in 2012. This difference compensates a reduction in the share of sub-national level schemes, whose number has remained very minimal overtime. The number of ELIS operating at supra-national levels (regional and international) have only moderately increased from $32 \%$ to $33 \%$ from 1990 to 2012, with most of the increase seen at the regional level. 
Figure 10. Evolution of the total number of ELIS by standard origin and scope

Upper panel: number of ELIS by region of origin. Lower panel: number of ELIS by the geographical scope from subnational to national, regional (continental) or international (covering countries in multiple continents)
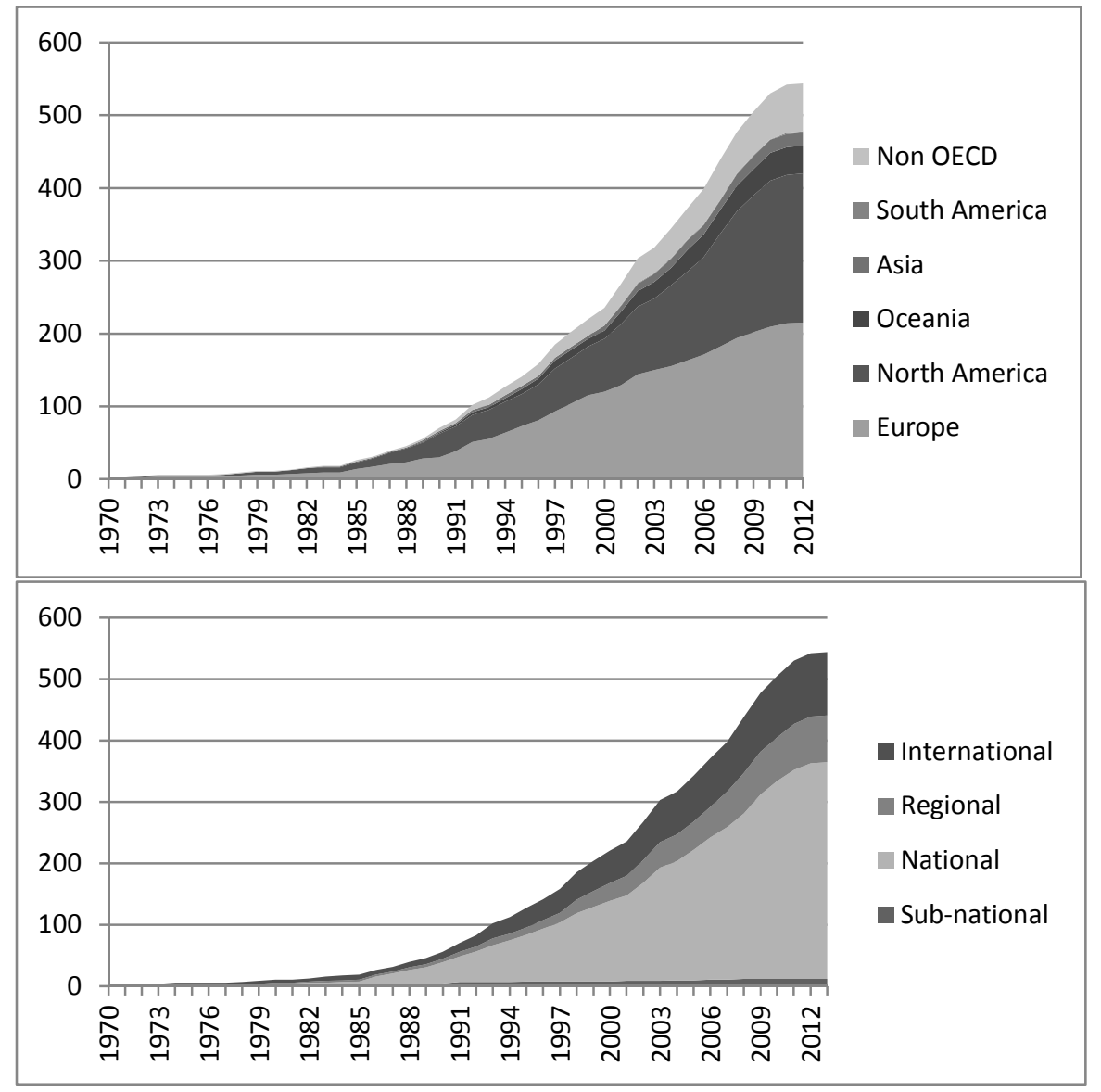

Source: Derived from the combined dataset.

The overwhelming increase of national ELIS is not surprising, as schemes tend to be initially set up at the national level. Whether these recently created ELIS go beyond this scope would be interesting to analyse. If certain schemes based on similar or compatible standards can be subject of international harmonisation efforts, others will try to expand and aim at competing with others beyond the border.

\subsection{Discussion}

\section{A dual growth process}

To synthesise the findings of this multiple-criteria trend analysis, Table 6 lists the characteristics leading the growth in absolute versus relative terms, taking the reference period 1990-2012. Single-issue labels, targeting food and agriculture, chemicals and natural resources, introduced in Europe and North America or operating at the national level constitute the most important group of introduced ELIS in absolute value during this period. In contrast, in relative terms, privately-led voluntary type III B2B schemes, focusing on energy, transportation and biofuels, covering climate and energy, introduced in Oceania and non-OECD countries or operating at the regional level represent the fastest growing segments of ELIS during this period. 
Table 6. Leading characteristics in the observed growth in the number of ELIS

\begin{tabular}{|c|c|c|c|c|}
\hline & $\begin{array}{l}\text { Leading characteristics } \\
\text { (absolute growth) }\end{array}$ & $\begin{array}{l}\text { Difference } \\
2012-1990\end{array}$ & $\begin{array}{l}\text { Leading characteristics } \\
\text { (relative growth) }\end{array}$ & $\begin{array}{c}\text { Ratio } \\
2012 / 1990\end{array}$ \\
\hline $\begin{array}{l}\text { Communication } \\
\text { channel }\end{array}$ & $\mathrm{B} 2 \mathrm{C}$ & 333 & B2B & 12.4 \\
\hline $\begin{array}{l}\text { Communication } \\
\text { mode }\end{array}$ & $\begin{array}{l}\text { Single-issue labels } \\
\text { (excluding organics) }\end{array}$ & 215 & $\begin{array}{l}\text { Type III and } \\
\text { Single-issue labels (excluding } \\
\text { organics) }\end{array}$ & $\begin{array}{c}\infty \\
31.7\end{array}$ \\
\hline $\begin{array}{l}\text { Communication } \\
\text { scope }\end{array}$ & $\begin{array}{l}\text { Food and agricultural } \\
\text { products } \\
\text { Multiple product coverage }\end{array}$ & $\begin{array}{l}94 \\
87\end{array}$ & $\begin{array}{l}\text { Energy, transportation and } \\
\text { biofuels }\end{array}$ & 72.2 \\
\hline $\begin{array}{l}\text { Environmental } \\
\text { attributes }\end{array}$ & $\begin{array}{l}\text { Chemicals and } \\
\text { Natural Resource }\end{array}$ & $\begin{array}{l}97 \\
91\end{array}$ & $\begin{array}{l}\text { Climate and } \\
\text { Energy }\end{array}$ & $\begin{array}{l}23.7 \\
17.2\end{array}$ \\
\hline $\begin{array}{l}\text { Standard } \\
\text { ownership }\end{array}$ & $\begin{array}{l}\text { Non-profit and } \\
\text { Private }\end{array}$ & $\begin{array}{l}239 \\
151 \\
\end{array}$ & Private & 14.7 \\
\hline $\begin{array}{l}\text { Mode of } \\
\text { governance }\end{array}$ & Voluntary & 457 & Voluntary & 7.9 \\
\hline Transparency & $\begin{array}{l}\text { Not open process } \\
\text { Open and published list }\end{array}$ & $\begin{array}{l}159 \\
139 \\
\end{array}$ & $\begin{array}{l}\text { Open process } \\
\text { Open process and published list }\end{array}$ & $\begin{array}{l}24 \\
11 \\
\end{array}$ \\
\hline Monitoring & Third-party & 209 & Third -party & 10.5 \\
\hline $\begin{array}{l}\text { Method of } \\
\text { assessment }\end{array}$ & Non-LCAs & 390 & LCAs & 9.4 \\
\hline Standard focus & nprPPMs & 284 & $\begin{array}{l}\text { Product standards and } \\
\text { services }\end{array}$ & $\begin{array}{l}16.5 \\
12.1\end{array}$ \\
\hline $\begin{array}{l}\text { Standard origin } \\
\text { and scope }\end{array}$ & $\begin{array}{l}\text { Europe and } \\
\text { North America, } \\
\text { National scope }\end{array}$ & $\begin{array}{l}185 \\
173 \\
311\end{array}$ & $\begin{array}{l}\text { Oceania, } \\
\text { Non-OECD countries, } \\
\text { Regional scope }\end{array}$ & $\begin{array}{c}19 \\
16.5 \\
10.9\end{array}$ \\
\hline
\end{tabular}

Source: Author.

Put together, these trends indicate that the growth in ELIS has not been uniform, but also that it results from two different and somewhat opposite driving factors.

- First, the overall growth in ELIS has been mainly driven by the increase in the number of traditional labelling schemes, covering in particular third-party certified environmental seals on food and agricultural products. The Marine Stewardship Council is an example of scheme matching these characteristics, it is a single-issue B2C label, providing natural resource information on food products, relying on a non-LCA based standard managed openly by a nonprofit, using third-party monitoring. Other schemes present some of these features, including organic food schemes such as Krav organics (Box 1). Overall, this "deepening" evolution or "intensification" may have generated competition for certain products, with potential positive or negative implications for consumers and the environment.

- This phenomenon has been accompanied by a reduced but more rapid introduction of a second type of schemes, including for instance private $\mathrm{B} 2 \mathrm{~B}$ reporting mechanisms on greenhouse gas emissions or schemes based on LCA methods. Examples matching most of these characteristics include ISO type III B2B standards, like the Global Green Tag (Box 1), private biofuel standards, carbon footprint and energy efficiency schemes. In contrast to the first driving factor, this "broadening" evolution or "extensification" process may not create relatively as much competitive pressure on the ELIS market, especially if it focuses on different products and 
services, but rather introduce different types of labels that could become more dominant as time passes. ${ }^{16}$

To assess the proportion of growth induced by these two driving forces, the main factors listed in the second and fourth column of Table 6 were selected and used to compute average growth shares and standard deviations. ${ }^{17}$ The results of these computations are shown in Figure 11, with a four-period fiveyear decomposition of growth. On the one hand, the dominant factors, including traditional schemes, represent a relatively diminishing proportion of the growth in ELIS numbers, declining in average from $34 \%$ to $31 \%$ of cumulative growth from 1991 to 2012 (lower panel of Figure 10). On the other hand, the emerging forces, including new schemes, augment gradually, representing $17 \%$ to $23 \%$ of the growth by period (upper panel) and representing from 14 per cent up to $18 \%$ of total cumulative growth in 2012 compared to 1991 . Figure 11 also shows that these average shares vary largely across categories, with increasingly overlapping confidence intervals.

\footnotetext{
16 The addition of new emerging schemes could increase competition with traditional schemes if present on the same products or services.

The leading variables standing for B2C, single attribute labels, food and agriculture and multiple product coverage, chemical and natural resources, non-profit voluntary, not LCA based, not open process, nprPPMs, Europe and national scope are used for the first type. Conversely, the leading variables standing for B2B, type III, energy, transportation and biofuel products, climate and energy coverage, private voluntary, LCA based, open process (with and without published list), product standard and services, Oceania and regional scope are used for the second type.
} 
Figure 11. Breakdown of growth in dominant versus emerging characteristics between 1991 and 2012 Upper panel: share of growth per period. Lower panel: Share of cumulated growth.

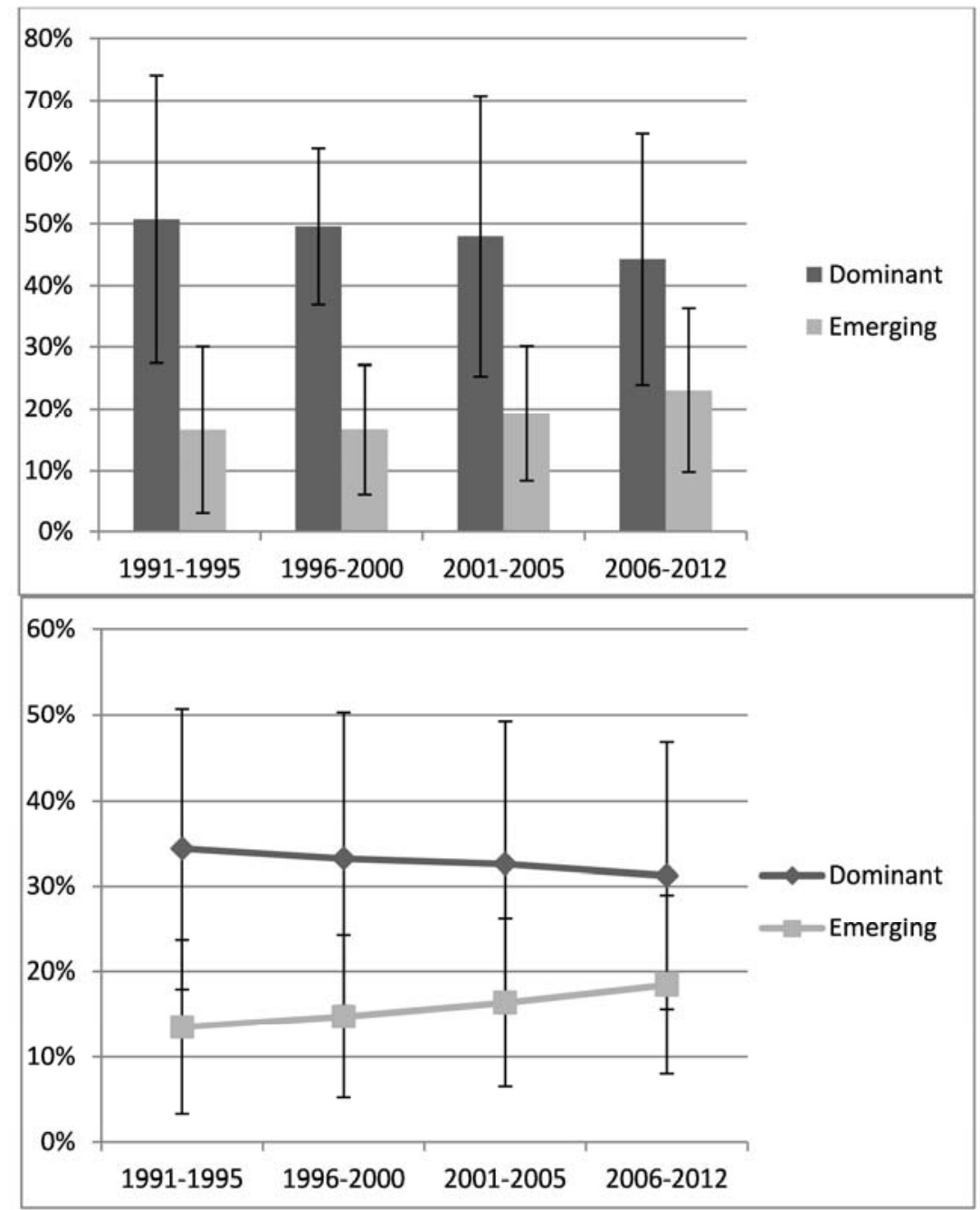

Source: Author, based on combined dataset.

These findings are consistent with an incentive-based interpretation of reduced intensification and increased extensification. Introducing a new scheme makes economic sense only if there is a sufficient expected demand. Just like in branding, two types of product differentiation may operate; vertical differentiation, for which product have intrinsic quality differences that can be ranked as such by all users, and horizontal differentiation where products compete for users that have different preferential rankings among options (Tirole, 2000). In the context of ELIS, an environmental seal aims to mark a quality difference for all products compared to the same products that do not carry the seal. In contrast, comparing products bearing alternative ELIS may result in different rankings based on users' preferences. ${ }^{18}$

Adding more schemes of the same type, or that are targeting the same products as observed in the case of intensification, is bound to increase competition (horizontal differentiation), further occupy the

18 Such horizontal product differentiation is illustrated by the classical economic example of Hotelling (1929), whereby shops compete for customers in a linear city, choosing the right spacing and prices to maximize their expected profits. 
market, which ultimately leads to reduced incentive for any standard-setter or entrepreneur to enter the information space. In contrast, adding relatively new schemes, focusing on different products and users, or in different countries (vertical differentiation), as observed in the case of extensification, lowers the competitive pressure, and is therefore bound to create more opportunity for stakeholders to introduce additional ELIS.

At the same time, the results shown in Figure 11 (lower panel) also imply that the intensification process represents a much larger share than the extensification process in the overall growth in ELIS. Therefore, competition may not represent such a barrier to the introduction of ELIS. Gaps are likely found even in traditional sectors, for which information disclosure schemes may already be in place and facilitate the introduction of new ones. It may also be easier to set up a new "seal" certified scheme, even if only marginally different to pre-existing ones, if the targeted users are already familiar with environmental performance differentiation. Such introduction could be further eased by supporting institutions that help ELIS suppliers move forward toward credibility, and by inventorying institutions that can provide reviews of schemes to users. Conversely, starting non-traditional schemes based on advanced computation methods, focusing on reporting carbon footprints for instance, remains more complex and perhaps more risky to undertake, given uncertainties in accepted methodologies and with the reaction of users.

These two interpretations may also follow each other sequentially. Any new scheme in its category starts by creating a market niche, facing limited competition, but with challenges to reach its users. Carbon footprint labels may still be trying to create space on consumer good markets. As times passes and assuming they are successful, other ELIS join the market with their own similar scheme, to a point where quality differentiation becomes horizontal, and competition moves to prices and quantities.

\section{ELIS coverage, gaps and overlaps}

To complete this overview of trends, a preliminary cross-variable analysis is run to assess whether similar ELIS are seen on the market. More specifically, the number of consumer ELIS (labels) covering the same products and environmental areas, originated from a specific region are computed using the relevant indicator variables. The results of these computations are shown in Table 7 for OECD countries in North America, Europe, Asia and Oceania. ${ }^{19}$

19 Labels covering multiple areas (like type I ecolabels) are noted multiple times in their respective rows of Table 7. 
Table 7. Number of labelling schemes in four regions of OECD countries covering selected products and areas in 2012

\begin{tabular}{|c|c|c|c|c|c|c|c|}
\hline & Waste & Energy & $\begin{array}{c}\text { Natural } \\
\text { Resource }\end{array}$ & $\begin{array}{l}\text { Climate } \\
\text { change }\end{array}$ & Biodiversity & $\begin{array}{c}\text { Chemical } \\
\text { control }\end{array}$ & $\begin{array}{l}\text { Other } \\
\text { areas }\end{array}$ \\
\hline \multicolumn{8}{|l|}{ North America } \\
\hline Food and agricultural products & 12 & 3 & 28 & 5 & 28 & 32 & 12 \\
\hline Textile and forest products & 9 & 6 & 19 & 6 & 9 & 14 & 5 \\
\hline Buildings, Furniture & 19 & 19 & 21 & 13 & 1 & 28 & 11 \\
\hline Energy, Transportation & 6 & 8 & 7 & 17 & 3 & 8 & 3 \\
\hline Tourism, Financial & 4 & 2 & 3 & 1 & 1 & 2 & 4 \\
\hline Appliances, electronics & 8 & 7 & 8 & 6 & 2 & 10 & 4 \\
\hline Consumer goods & 4 & 2 & 3 & 3 & 1 & 8 & 7 \\
\hline Multiple & 28 & 19 & 21 & 21 & 12 & 25 & 16 \\
\hline Other product & 11 & 4 & 5 & 6 & 4 & 12 & 7 \\
\hline \multicolumn{8}{|l|}{ Europe (OECD) } \\
\hline Food and agricultural products & 9 & 5 & 38 & 8 & 36 & 37 & 13 \\
\hline Textile and forest products & 18 & 7 & 30 & 5 & 17 & 28 & 9 \\
\hline Buildings, Furniture & 14 & 13 & 19 & 8 & 6 & 18 & 12 \\
\hline Energy, Transportation, & 3 & 15 & 6 & 13 & 3 & 4 & 2 \\
\hline Tourism, Financial & 10 & 6 & 12 & 9 & 9 & 9 & 5 \\
\hline Appliances, electronics & 6 & 9 & 6 & 0 & 1 & 9 & 6 \\
\hline Consumer goods & 3 & 1 & 6 & 4 & 2 & 6 & 0 \\
\hline Multiple & 20 & 15 & 25 & 17 & 14 & 24 & 10 \\
\hline Other product & 3 & 1 & 2 & 1 & 1 & 3 & 1 \\
\hline \multicolumn{8}{|l|}{ Oceania (OECD) } \\
\hline Food and agricultural products & 2 & 1 & 6 & 2 & 4 & 6 & 4 \\
\hline Textile and forest products & 0 & 0 & 2 & 0 & 0 & 1 & 2 \\
\hline Buildings, Furniture & 0 & 2 & 0 & 0 & 0 & 0 & 0 \\
\hline Energy, Transportation, & 0 & 6 & 0 & 3 & 0 & 0 & 1 \\
\hline Tourism, Financial & 1 & 1 & 2 & 1 & 2 & 2 & 0 \\
\hline Appliances, electronics & 0 & 3 & 0 & 0 & 0 & 0 & 0 \\
\hline Consumer goods & 1 & 0 & 1 & 0 & 1 & 1 & 0 \\
\hline Multiple & 6 & 1 & 6 & 4 & 3 & 4 & 4 \\
\hline Other product & 1 & 1 & 1 & 0 & 0 & 1 & 1 \\
\hline \multicolumn{8}{|l|}{ Asia (OECD) } \\
\hline Food and agricultural products & 0 & 0 & 1 & 0 & 1 & 1 & 0 \\
\hline Textile and forest products & 0 & 0 & 1 & 0 & 1 & 1 & 0 \\
\hline Buildings, Furniture & 1 & 1 & 1 & 1 & 0 & 2 & 1 \\
\hline Energy, Transportation, & 0 & 2 & 0 & 1 & 0 & 0 & 0 \\
\hline Tourism, Financial & 0 & 0 & 0 & 0 & 0 & 0 & 0 \\
\hline Appliances, electronics & 0 & 2 & 0 & 0 & 0 & 0 & 0 \\
\hline Consumer goods & 0 & 0 & 0 & 0 & 0 & 0 & 0 \\
\hline Multiple & 2 & 4 & 3 & 5 & 1 & 3 & 1 \\
\hline Other product & 0 & 0 & 0 & 1 & 0 & 0 & 1 \\
\hline
\end{tabular}

Source: Author's derivations from the combined dataset.

These tables suggest that the four regions do not share the same likelihood of consumer label competitions. In the each region, some specific product categories and environmental areas may be more likely to be subject to multiple labels than others. In North America, food and agricultural products; textile and forest products, and energy related and transportation goods are more prone to coverage by multiple labels, especially labels covering chemical control and natural resource management for the first two, and 
climate for the third category of products. In Europe, textile and forest products are less concerned by this phenomenon, while buildings and furniture labels and labels covering multiple categories of goods coexist in seemingly higher competitive contexts. In Oceania, areas of potential overlap are found especially for labels focusing on natural resources and chemical controls, including in food and agriculture products. With regards to Asia, the only areas with potential competition in labels in the combined dataset are found in the case of climate change and energy. At the same time, numbers presented here are subject to an important caveat; in this simplified analysis conducted at the aggregate level, a number of schemes actually remain in countries of their respective regions.

Beyond this simplified numerical example, the method presented here could be used when assessing the impacts of the multiplication of ELIS on specific product categories. The method could be refined to assess the likelihood of similar schemes including at the national level in different countries, and for different communication channels and means. This would enable drawing a map of hotspots, isolating specific types of ELIS for which competition is bound to be prominent at a determined scale. Furthermore, it would help single-out the actual impacts of ELIS increases rather than the overall global increase in ELIS.

\section{Conclusions}

This report provides a comprehensive overview of the complex and dynamic landscape of environmental labelling and information schemes (ELIS). First, a review of initiatives and actors, outlining their roles and interactions, is used to build an institutional map of the diversity of schemes. The conceptual framework it suggests highlights the importance of five types of institutions evolving around ELIS suppliers and users: supporting institutions, inventorying institutions, policy support institutions, platforms and consortiums and framing institutions.

Second, the ELIS universe is dissected based on a set of identified characteristics affecting ELIS communication modes and the nature of the standards on which they are based. Interactions between criteria are discussed, outlining various categories of ELIS related to their communication means, with environmental seals based on certification, comprehensive reports or footprinting, and intermediate schemes reporting simplified semi-quantitative information. The importance of public standards in this landscape is emphasised, with a discussion of the multiple roles governments can play in the use of ELIS.

Lastly, an original empirical analysis of the growth in ELIS is conducted, based on a global dataset of 544 ELIS introduced between 1970 and 2012. General trends drawn from this dataset support the rapid increase in the number of ELIS, especially in the late 1990s and in the period 2007-2010. But they also raise the possibility that growth may be slowing down. The analysis shows both the diversity and unequal distribution of ELIS growth according to various characteristics, such as communication means, channels, scope, and the standards on which they are based. In particular, several shifts are noted, including from organic certification and ecolabels to single-issue labels and ISO type III labels, from non-profit to privately-owned ELIS, or from biodiversity to climate change related schemes. A high proportion of ELIS in the database does not use life-cycle approaches and is based on standards relying on non-product-related process and production method. A majority of these schemes also operate at the national level and a growing share of ELIS uses third-party auditing or verification. Most ELIS remain non-transparent in their standard-setting process, though there is a limited but relatively fast increase in transparent schemes during the period covered.

The results further outline the dual nature of the evolution of ELIS. First, the multiplication of schemes is driven by an increase in large categories of traditional ELIS, including certified seals set up by non-profit organisations on ranges of food and agricultural products, representing altogether an estimated average $31 \%$ of total cumulative growth. Second, the multiplication is driven by an emerging and 
accelerating trend introducing new, private ELIS which cover quantitative, life-cycle based reporting of energy and carbon in particular. This trend represents an average $18 \%$ of the growth. This combination of drivers highlights a possible tension between increased competition among similar ELIS, which seems to be slowing down in recent years, and the emergence of new schemes potentially less exposed to competition but facing larger entry challenges.

Lastly, the dataset shows that the multiplicity of ELIS may not be observed for all products and all environmental areas in all countries. This finding is important when moving towards discussing the possible economic, environmental, and trade impacts of ELIS. The ELIS universe, even if it presents a multiplicity of schemes, appears to have more gaps than overlaps in certain areas. In this context, the observed continued introduction of new ELIS may result from the gap-filling opportunities that exist where the demand for information has not yet been satisfied. In other cases, it may be driven by the fact that the characteristics of existing schemes do not fit the objectives or intrinsic peculiarities of ELIS developers. Or it may be grounded on more fundamental economic reasons, whereby an internal, customised environmental standard route is preferable to using pooled certification schemes.

At the policy level, the first relevant issue raised by these results is the potential implications of the multiplication of schemes in specific areas, and the overall continued increase in the supply of information. Increased competition and number of schemes may encourage wider market coverage of green products, lessening the overall environmental impacts of economic activities, but misleading information or inaccurate schemes could also lead to a lower effectiveness of all schemes and to possible trade distortions. At the same time, the progressive change in the nature of the recently introduced ELIS reported herein has to be accounted for in any attempt at determining the welfare effects associated with the multiplication of schemes. Moreover, the evolution of multiple spheres of interacting institutions described in this report also has to be considered to create a sufficiently credible counterfactual on which to base a policy analysis.

The second important policy question is whether any type of public response might be needed. The report has outlined the observed roles of governments either internally or externally, as supplier, sponsor, supporter, promoter, guide or regulator of ELIS. Whether and how one or more of these roles needs to be changed at the national or international level will depend on the presence of identified impacts and their comparison with a well-grounded counterfactual.

These questions will be examined in the next stages of the project, which will look at evidence on the trade and environmental implications of having a multiplicity of schemes, and analyse in more detail governments' current and potential policy responses to identified challenges. 


\section{REFERENCES}

Allison, C. and A. Carter (2000), "Study on different types of Environmental Labelling (ISO Type II and III Labels): Proposal for an Environmental Labelling Strategy", Report for the European Commission, Environmental Resource Management, Oxford, UK.

Beltramello, A. (2012), "Market Development for Green Cars", OECD Green Growth Papers, No. 2012/03, OECD Publishing. http://dx.doi.org/10.1787/5k95xtcmxltc-en

BigRoom (2013), EcoLabel Index, updated as of April 2013, www.ecolabelindex.com, accessed April 2013.

Blackman, A., et al. (2012). "Does Tourism Eco-Certification Pay? Costa Rica's Blue Flag Program", Discussion Paper 12-50, Resources for the Future, Washington DC, USA.

CIPO (Canadian Intellectual Property Office) (2013), Canadian Trade-marks Database, CIPO, Government of Canada, Ottawa, Canada, www.ic.gc.ca/app/opic-cipo/trdmrks/srch/tmSrch.do?lang=eng, accessed February 2013.

Capozza, I. (2011), "Greening Growth in Japan", OECD Environment Working Papers, No. 28, OECD Publishing, Paris. http://dx.doi.org/10.1787/5kggc0rpw551-en

Ceci-Renaud, N. and W. Thao Khamsing (2012), "Les consommateurs face à l'affichage environnemental". Études et Documents No 74, Commissariat Général au Développement Durable, Ministère de l'Écologie, du Développement Durable et de l'Énergie, Paris, France.

Chang, H.-H. (2012), "Does the use of eco-labels affect income distribution and income inequality of aquaculture producers in Taiwan?" Ecological Economics, 80, 101-108.

Christian, C., et al. (2013), "A review of formal objections to Marine Stewardship Council fisheries certifications", Biological Conservation, 161, 10-17.

Cohen, M. A. and M.P. Vandenbergh (2012), "The potential role of carbon labeling in a green economy" Energy Economics 34 Supplement 1: S53-S63.

Comas Martí, J. M. and R.W. Seifert (2012), "Reviewing the adoption of ecolabels by firms," A Survey Report, EPFL - IMD International, Switzerland.

Conrad, C. (2011), "Processes and Production Methods (PPMs) in WTO Law: Interfacing Trade and Social Goals". Cambridge University Press, Cambridge, UK.

Crespi, J.M. and S. Marette (2005), "Eco-labelling economics: is public involvement necessary?" in Krarup, S., Russell, C. S. (eds.), Environment, Information and Consumer Behaviour, Edgar Elward Publishing, Northampton, MA. 
Dahl, R. (2012), "Greenwashing: Do you know what you're buying?" Environmental Health Perspectives 118(6):A246-A252.

Daniells, S. (2013), "Americans still wary of 'greenwashing', including organic labels: Harris Poll", FoodNavigator, April 17 2013, www.foodnavigator-usa.com/Market/Americans-still-wary-ofgreenwashing-including-organic-labels-Harris-Poll, accessed March 202013.

Earley, J. and L. K. Anderson (2003), "Developing-country access to developed-country markets under selected eco-labelling programmes" [COM/ENV/TD(2003)30/FINAL], OECD, Paris, France.

EPA (U.S. Environmental Protection Agency) (2013), EPA Smartway website, www.epa.gov/smartway/index.htm, accessed February 2013.

Ernst \& Young and Quantis (2010), "Product Carbon Footprinting - a study on methodologies and initiatives", Final Report for the European Commission DG Environment, Ernst \& Young and Quantis, Brussels, Belgium.

European Commission (2012), "Impact Assessment. Commission Staff Working Document Accompanying the document Communication from the Commission on Building the Single Market for Green Products: Facilitating better and credible information on environmental performance of products and organizations", European Commission Brussels, Belgium, http://eurlex.europa.eu/LexUriServ/LexUriServ.do?uri=SWD:2013:0111:FIN:EN:PDF, accessed April 2013.

European Commission (2013), "Commission Recommendation on the use of common methods to measure and communicate the life cycle environmental performance of products and organizations", European Commission, Brussels, Belgium, http://ec.europa.eu/environment/eussd/smgp/pdf/recommendation.pdf, accessed April 2013.

EVEA et Savin Martinet Associés (2012),"Comparaison des ACV et affichages carbone utilisés dans le monde sur les produits agricoles et agroalimentaires: étude technique et juridique", Étude pour le Ministère de l'Agriculture (MAAPRAT), Paris, France.

Fliess, B., et al. (2007), "CSR and Trade: Informing Consumers about Social and Environmental Conditions of Globalised Production: Part I", OECD Trade Policy Papers, No. 47, OECD Publishing, Paris. http://dx.doi.org/10.1787/246322000033.

GEN (Global Ecolabelling Network) (2013), GEN Website, www.globalecolabelling.net/, accessed February 2013.

Global Fuel Economy Initiative (2013), Website of the United Nations Environmental Program, UNEP, Nairobi, Kenya, www.unep.org/transport/gfei/autotool/approaches/information/labeling.asp, accessed March 2013.

Hatanaka, M., C. Bain and L. Busch (2005), "Third-party certification in the global agrifood system", Food Policy, 30(3), 354-369.

Hotelling, H. (1929) "Stability in competition", Economic Journal 39 (153): 41-57.

INPIT (National Center for Industrial Property Information and Training) (2013), Industrial Property Digital Library, Trademark Database, Tokyo, Japan, http://www3.ipdl.inpit.go.jp/cgibin/ET/ep_main.cgi?1367326735473, accessed February 2013. 
IP Australia (2013), Australian Trade Mark On-line Search System, Australian Government, Canberra, Australia, http://pericles.ipaustralia.gov.au/atmoss/falcon.application_start, accessed February 2013.

ISO (International Organization for Standardization) (1999a), "Environmental labels and declarations Type I environmental labelling - Principles and procedures.” ISO 14024:1999. ISO, Geneva, Switzerland.

ISO (1999b), "Environmental labels and declarations - Self-declared environmental claims (Type II environmental labelling)", ISO 14021:1999. ISO, Geneva, Switzerland.

ISO (1999c), "Environmental labels and declarations - Environmental labelling Type III - Guiding principles and procedures", ISO/DTR 14025. ISO, Geneva, Switzerland.

ITC (International Trade Centre) (2012), "The Interplay of Public and Private Standards: Literature Review Series on the Impacts of Private Standards; Part 3", International Trade Centre, Geneva, Switzerland.

JEMAI (Japan Environmental Management Association for Industry) (2013). EcoLeaf Environmental Label Website, www.ecoleaf-jemai.jp/eng/, accessed April 2013.

Kang, S., J. Oh and H. Kim (2012), "Korea's Low-Carbon Green Growth Strategy", OECD Development Centre Working Papers, No. 310, OECD Publishing. http://dx.doi.org/10.1787/5k9cvqmvszbr-en

KEITI (Korean Environmental Industry and Technology Institute (2013). Environmental Declaration of Product website, www.edp.or.kr/edp/english/main/main.asp, accessed April 2013.

Kewalramani, D. and R. J. Sobelsohn (2012), "Are you being greenwashed?" New York State Bar Association Journal 85(5).

KIPRIS (Korean Intellectual Property Rights Information Service) (2013), Trademark database, Saoeogu, Republic of Korea, http://engdtj.kipris.or.kr/engdtj/searchLogina.do?method=loginTM, accessed February 2013.

Lohr, L. (1998), “Welfare effects of eco-label proliferation: Too much of a good thing?" Working Paper, Department of Agriculture and Applied Economics 98-22. Athens, GA: University of Georgia. http://ageconsearch.umn.edu/bitstream/16642/1/fs9822.pdf, accessed October 132012.

Low, P., G. Marceau and J. Reinaud (2011). "The Interface Between the Trade and Climate Change Regimes: Scoping the Issues" World Trade Organization Staff Working Paper ERSD-2011-1, WTO, Geneva, Switzerland.

Mak, H. (2013),"Eco-labels: Radical rethink required.” Ethical Corporation's Magazine, 17/01/2012. http://www.ethicalcorp.com/environment/eco-labels-radical-rethink-required, accessed January 2013.

Marette, S. (2007), "The labels in agriculture, their impact on trade and the scope for international policy action" chapter 8 in Grote, U., Basu, A.K. and Chau, N.H.(eds.), New Frontiers in Environmental and Social Labeling, Physica Verlag, Heidelberg, Germany.

Mazur, E. (2012), "Green Transformation of Small Businesses: Achieving and Going Beyond Environmental Requirements", OECD Environment Working Papers, No. 47, OECD Publishing, Paris. http://dx.doi.org/10.1787/5k92r8nmfgxp-en 
Motaal, D. A. (1999) "Eco-labelling and the World Trade Organization" in OECD, "Conclusions and papers presented at the International Conference Green Goods V 'Eco-labelling for a sustainable future" [ENV/EPOC/PPC(99)4/FINAL], OECD, Paris, France.

Moïsé, E. and R. Steenblik (2011), "Trade-Related Measures Based on Processes and Production Methods in the Context of Climate-Change Mitigation", OECD Trade and Environment Working Papers, No. 2011/04, OECD Publishing. http://dx.doi.org/10.1787/5kg6xssz26jg-en

Norwegian Industrial Property Office (2013), Trademark database, Oslo, Norway, https://dbsearch2.patentstyret.no/AdvancedSearch.aspx?Category=Mark, accessed February 2013.

OECD (1976), "The energy label: a means of energy conservation" Report by the OECD Committee on Consumer Policy, OECD, Paris, France.

OECD (1991), “Environmental labelling in OECD countries”, OECD, Paris, France.

OECD (1994a), "Summary Report of the Workshop on Life-Cycle Management and Trade." [OCDE/GD(94)8], OECD, Paris, France

OECD (1994b), "Trade and Environment: Processes and Production Methods", OECD, Paris, France

OECD (1997a), “Eco-labelling: Actual effects of selected programmes”, OECD, Paris, France.

OECD (1997b), "PPMs: Conceptual framework and considerations on the use of PPM-based trade measures", OECD, Paris, France.

OECD (1999), "Conclusions and papers presented at the International Conference Green Goods V 'Ecolabelling for a sustainable future"” [ENV/EPOC/PPC(99)4/FINAL], OECD, Paris, France.

OECD (2003), "Analysis of non-tariff measures: The case of labelling: Overview and analysis of WTO data" [TD/TC/WP(2002)40/FINAL], OECD, Paris, France.

OECD (2005), "Effects of eco-labelling schemes: Compilation of recent studies" [COM/ENV/TD(2004)34/FINAL], OECD, Paris, France.

OECD (2007), Instrument Mixes for Environmental Policy, OECD Publishing, Paris. http://dx.doi.org/10.1787/9789264018419-en

OECD (2009a), "Round table on eco-labelling and certification in the fisheries sector" [TAD/FI(2009)14], OECD, Paris, France.

OECD (2009b), "Counting carbon in the marketplace: Part 1-Overview Paper" [COM/TAD/ENV/JWPTE(2009)7/ANN], OECD, Paris, France.

OECD (2009c), "Transparency practices of voluntary certification schemes: Draft report" [TAD/TC/WP(2009)39], OECD, Paris, France.

OECD (2010a), "Enhancing the value and effectiveness of environmental claims: Protecting and empowering consumers. Report on the OECD workshop" [DSTI/CP(2010)18], OECD, Paris, France. 
OECD (2010b), Transition to a Low-Carbon Economy: Public Goals and Corporate Practices, OECD Publishing, Paris. http://dx.doi.org/10.1787/9789264090231-en

OECD (2011a), Fisheries and Aquaculture Certification, OECD Publishing, Paris. http://dx.doi.org/10.1787/9789264119680-en

OECD (2011b), Greening Household Behaviour: The Role of Public Policy, OECD Studies on Environmental Policy and Household Behaviour, OECD Publishing, Paris. http://dx.doi.org/10.1787/9789264168060-en

OECD (2012), Water Quality and Agriculture: Meeting the Policy Challenge, OECD Studies on Water, OECD Publishing, Paris. http://dx.doi.org/10.1787/9789264168060-en

OECD (2013), "Synergies between private standards and public regulation-Scoping Paper" [TAD/TC/CA/WP(2013)1], OECD, Paris, France.

Ottman, J.A. (2011), “The new rules of green marketing”, Berrett-Koehler Publishers, San Francisco, USA.

Overgaard, S. (2012), “As US States consider to add food labels, Denmark looks to subtract some”. NPR the salt, October 29 2012, National Public Radio, Washington DC, www.npr.org/blogs/thesalt/2012/10/29/163869580/as-u-s-states-look-to-add-food-labels-denmarklooks-to-subtract-some?sc=tw\&cc=share, accessed April 2013.

PCF Projekt (2009a), "Bilan $\mathrm{CO}_{2}$ ” E. Leclerc, Information note, PEF Projekt, Berlin, Germany, www.pcfprojekt.de/files/1231514458/profile_bilan-co2-eleclerc.pdf, accessed March 2013.

PCF Projekt (2009b), CO2 Low Label (Level 2). Berlin, PEF Projekt, Berlin, Germany, www.pcfprojekt.de/files/1231517229/profile cool-label-korea.pdf, accessed March 2013.

République Française (2010), Loi n ${ }^{\circ}$ 2010-788 du 12 juillet 2010 portant engagement national pour l'environnement. Journal Officiel de la République Française nº0160 du 13 juillet 2010 page 12905, Paris, France, www.legifrance.gouv.fr/affichTexte.do;jsessionid=9EEBFFE97BC7EB683B97AB1509189CA6.tpd jo13v 3? cidTexte $=$ JORFTEXT000022470434\&dateTexte=20130423, accessed December 2012.

Swiss Federal Institute of Intellectual Property (2013), IP rights database, Bern, Switzerland, www.swissreg.ch/srclient/faces/jsp/trademark/sr1.jsp, accessed February 2013.

Tirole, J. (2000), “The theory of industrial organization”, MIT Press, Boston, MA, USA.

TMView (2013), Internet European Trade mark database, Brussels, Belgium, www.tmview.europa.eu/tmview/welcome.html, accessed March 2013.

Turkish Patent Institute (2013), Trademark research, Ankara, Turkey, http://online.tpe.gov.tr/trademark/servlet/ETMSearchServlet, accessed February 2013.

UNEP (United Nations Environmental Program) and IISD (International Institute for Sustainable Development) (2006), "Environment and Trade: A Handbook", Second Edition, IISD, Winnipeg, Canada, www.iisd.org/pdf/2005/envirotrade_handbook_2005.pdf, accessed February 2013. 
UNFSS (United Nations Forum on Sustainability Standards) (2013), Launching Conference Flyer. March 21-22 2013. UNFSS, Geneva, Switzerland, http://unfss.files.wordpress.com/2012/05/unfss_flyer_12_28_2013.pdf, accessed February 2013.

United Kingdom Intellectual Property Office, (2013), Trade mark database, Intellectual Property Office, London, UK, www.ipo.gov.uk/types/tm/t-os/t-find/tmtext.htm, accessed February 2013.

UNOPS (United Nations Office for Project Services) (2009), "A guide to environmental labels for Procurement Practitioners of the United Nations System”, UNOPS, Geneva, Switzerland.

USPTO (United States Patent and Trademark Office) (2013), Trademark database, U.S. Department of Commerce, Washington DC, http://tess2.uspto.gov/bin/gate.exe?f=searchst\&state=4803:vuwxlk.1.1, accessed February 2013.

Vergez, A. (2012), "Vers un affichage environnemental sur les produits alimentaires", Études et Documents No 64, Commissariat Général au Développement Durable, Ministère de l'Écologie, du Développement Durable et de l'Énergie, Paris, France.

Zwerdling, D. and M. Williams (2013), "Is Sustainable Seafood Really Sustainable?" NPR's All Things Considered, 11 February 2013, National Public Radio, Washington, DC, www.npr.org/2013/02/11/171376509/is-sustainable-labeled-seafood-really-sustainable, accessed March 2013. 


\section{ANNEX: TRADEMARK ANALYSIS}

The analysis was done based on reports from patent offices. The search was initially done on patent offices for Australia (IP Australia, 2013), Canada (CIPO, 2013), the EU (TMView, 2013), the United Kingdom (United Kingdom Intellectual Property Office, 2013), Japan (INPIT, 2013), Korea (KIPRIS, 2013), Norway (Norwegian Industrial Property Office, 2013), Switzerland (Swiss Federal Institute of Intellectual Property, 2013), Turkey (Turkish Patent Institute, 2013), and the United States (USPTO, 2013).

The three selected words were entered as keywords in the search menus, together with options for registered trademarks and the year of registration of the trademark. In case of the European Union, the TMView database was used; it combined data from 26 patent offices and the trademarks from the Office of Harmonization of the Internal Market (OHIM) system. However, it does not allow users to make a search based on the registration date. Instead, the filling dates of the registered trademark were used as reference. The United Kingdom was also combined separately due to a different search system not compatible with TMView.

The results are shown in Figures 12,13 and 14 for the seven countries with the largest numbers of relevant trademarks. The number of "Green" trademarks largely exceeds figures for the other two. As of December 31 2012, 3058 registered trademarks included the word "green" in the seven selected countries, with about a third in the United States. In contrast, 2543 included the word "natural" and only 238 used the word "sustainable". The pattern of the first two figures consistently shows a large increase up until a peak happening between 2008 and 2010 depending on the country. In contrast, trademarks with "natural", although increasing, do not exhibit any peak increase.

Figure 12. Introduction of registered trademarks using the word "Green" in selected countries

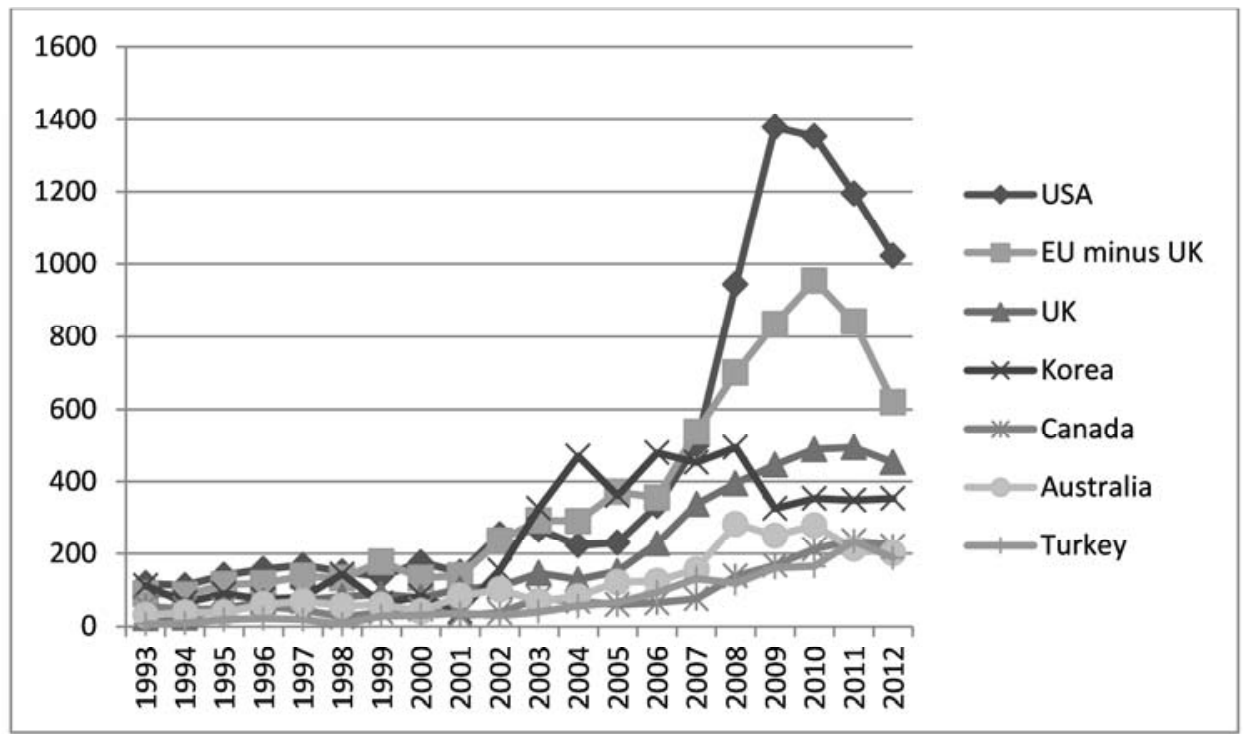

Sources: CIPO (2013), IP Australia (2013), KIPRIS (2013), TMView (2013), Turkish Patent Institute (2013), United Kingdom Intellectual Property Office (2013) and USPTO (2013). 
Figure 13. Introduction of registered trademarks using the word "Sustainable" in selected OECD countries

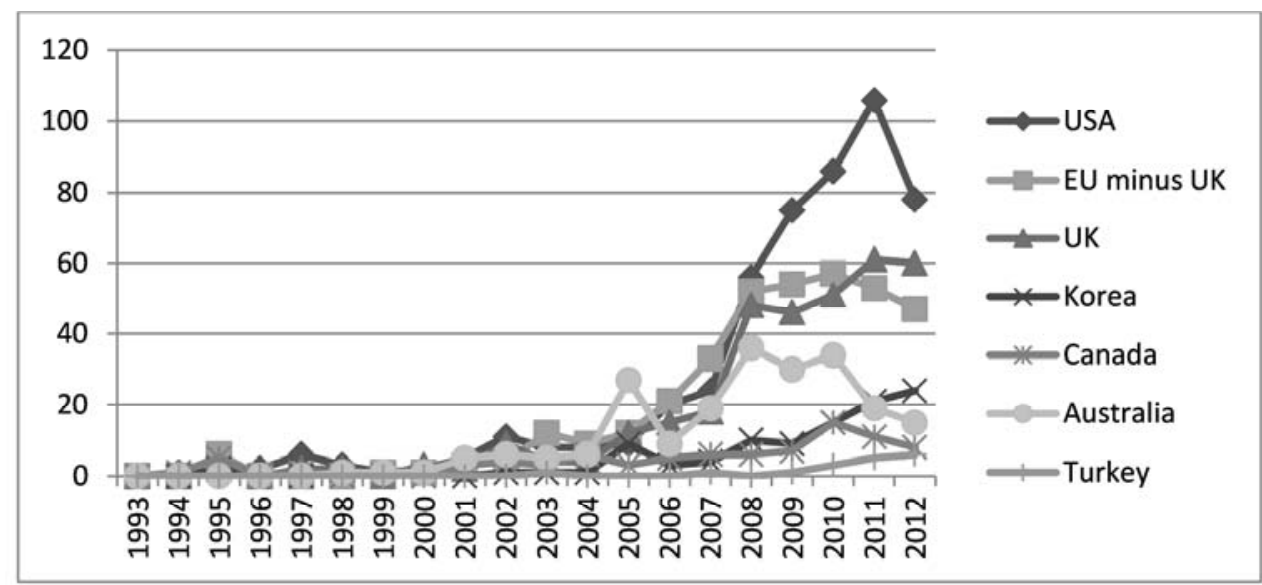

Sources: CIPO (2013), IP Australia (2013), KIPRIS (2013), TMView (2013), Turkish Patent Institute (2013), United Kingdom Intellectual Property Office (2013) and USPTO (2013).

Figure 14. Introduction of registered trademarks using the word "Natural" in selected OECD countries

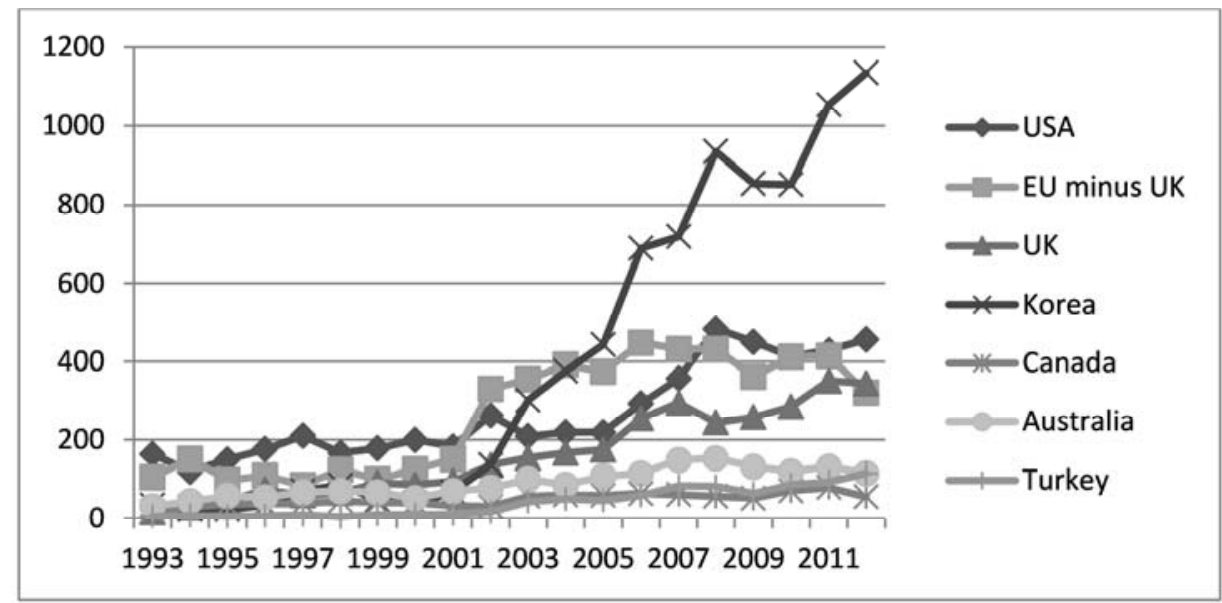

Sources: CIPO (2013), IP Australia (2013), KIPRIS (2013), TMView (2013), Turkish Patent Institute (2013), United Kingdom Intellectual Property Office (2013) and USPTO (2013).

To check for robustness, these results were confirmed with the analysis of trends in the relative number of trademarks (proportion of trademarks with the relevant words over the total of registered trademarks). The results show a similar peak growth pattern overall. All countries but Canada show a decrease in the growth of the share of "green" trademarks starting in 2010 following relative peaks. All reporting countries show a peak in the growth of the share of trademarks with the word "sustainable". And the United Kingdom and Korea present increasing shares of "natural" trademarks, while others are found to have limited fluctuations. At the same time, the leading countries differ when looking at shares rather than numbers of trademarks. In particular, the share of trademark with the word "green" is the largest in the United Kingdom, reaching a peak of growth of $1.80 \%$ around 2010 , while other countries reach peaks of growth under $0.90 \%$. 